University of Nebraska - Lincoln

DigitalCommons@University of Nebraska - Lincoln

Publications from USDA-ARS / UNL Faculty

U.S. Department of Agriculture: Agricultural

Research Service, Lincoln, Nebraska

2012

Two-source energy balance model estimates of

evapotranspiration using component and composite surface

temperatures

\author{
Paul Colaizzi \\ USDA-ARS, Paul.Colaizzi@ARS.USDA.GOV \\ William P. Kustas \\ USDA-ARS \\ Martha C. Anderson \\ USDA-ARS, martha.anderson@ars.usda.gov \\ Nurit Agam \\ Gilat Research Center, agam@agri.gov.il \\ Judy A. Tolk \\ USDA-ARS
}

See next page for additional authors

Follow this and additional works at: https://digitalcommons.unl.edu/usdaarsfacpub

Colaizzi, Paul; Kustas, William P.; Anderson, Martha C.; Agam, Nurit; Tolk, Judy A.; Evett, Steven R.; Howell, Terry A.; Gowda, Prasanna H.; and O’Shaughnessy, Susan A., "Two-source energy balance model estimates of evapotranspiration using component and composite surface temperatures" (2012). Publications from USDA-ARS / UNL Faculty. 1147.

https://digitalcommons.unl.edu/usdaarsfacpub/1147

This Article is brought to you for free and open access by the U.S. Department of Agriculture: Agricultural Research Service, Lincoln, Nebraska at DigitalCommons@University of Nebraska - Lincoln. It has been accepted for inclusion in Publications from USDA-ARS / UNL Faculty by an authorized administrator of DigitalCommons@University of Nebraska - Lincoln. 


\section{Authors}

Paul Colaizzi, William P. Kustas, Martha C. Anderson, Nurit Agam, Judy A. Tolk, Steven R. Evett, Terry A. Howell, Prasanna H. Gowda, and Susan A. O'Shaughnessy 


\title{
Two-source energy balance model estimates of evapotranspiration using component and composite surface temperatures ${ }^{\text {is }}$
}

\author{
Paul D. Colaizzi ${ }^{\mathrm{a}, *}$, William P. Kustas ${ }^{\mathrm{b}}$, Martha C. Anderson ${ }^{\mathrm{b}}$, Nurit Agam ${ }^{\mathrm{c}}$, Judy A. Tolk ${ }^{\mathrm{a}}$, \\ Steven R. Evett ${ }^{a}$, Terry A. Howell ${ }^{\text {a }}$, Prasanna H. Gowda ${ }^{\text {a }}$, Susan A. O'Shaughnessy ${ }^{a}$ \\ ${ }^{a}$ USDA-ARS Conservation and Production Research Laboratory, P.O. Drawer 10, Bushland, TX 79012, United States \\ ${ }^{\mathrm{b}}$ USDA-Agricultural Research Service, Hydrology \& Remote Sensing Laboratory, Bldg. 007, BARC-West, Beltsville, MD 20705, United States \\ ${ }^{\mathrm{c}}$ Gilat Research Center, Agricultural Research Organization, Rural delivery, Negev 85280, Israel
}

\section{A R T I C L E I N F O}

\section{Article history:}

Received 28 October 2011

Received in revised form 11 May 2012

Accepted 7 June 2012

Available online 15 June 2012

\section{Keywords:}

Evaporation

Transpiration

Evapotranspiration

Irrigation

Cotton

Remote sensing

\begin{abstract}
A B S T R A C T
The two source energy balance model (TSEB) can estimate evaporation (E), transpiration ( $T$ ), and evapotranspiration (ET) of vegetated surfaces, which has important applications in water resources management for irrigated crops. The TSEB requires soil $\left(T_{S}\right)$ and canopy $\left(T_{C}\right)$ surface temperatures to solve the energy budgets of these layers separately. Operationally, usually only composite surface temperature $\left(T_{R}\right)$ measurements are available at a single view angle. For surfaces with nonrandom spatial distribution of vegetation such as row crops, $T_{R}$ often includes both soil and vegetation, which may have vastly different temperatures. Therefore, $T_{S}$ and $T_{C}$ must be derived from a single $T_{R}$ measurement using simple linear mixing, where an initial estimate of $T_{C}$ is calculated, and the temperature - resistance network is solved iteratively until energy balance closure is reached. Two versions of the TSEB were evaluated, where a single $T_{R}$ measurement was used (TSEB- $T_{R}$ ) and separate measurements of $T_{S}$ and $T_{C}$ were used (TSEB- $T_{C}-T_{S}$ ). All surface temperatures $\left(T_{S}, T_{C}\right.$, and $\left.T_{R}\right)$ were measured by stationary infrared thermometers that viewed an irrigated cotton (Gossypium hirsutum $L$.) crop. The TSEB- $T_{R}$ version used a Penman-Monteith approximation for $T_{C}$, rather than the Priestley-Taylor-based formulation used in the original TSEB version, because this has been found to result in more accurate partitioning of $E$ and $T$ under conditions of strong advection. Calculations of $E, T$, and $E T$ by both model versions were compared with measurements using microlysimeters, sap flow gauges, and large monolythic weighing lysimeters, respectively. The TSEB- $T_{R}$ version resulted in similar overall agreement with the TSEB- $T_{C}-T_{S}$ version for calculated and measured $E\left(R M S E=0.7 \mathrm{~mm} \mathrm{~d}^{-1}\right)$ and better overall agreement for $T\left(R M S E=0.9\right.$ vs. $\left.1.9 \mathrm{~mm} \mathrm{~d}^{-1}\right)$, and $E T(R M S E=$ 0.6 vs. $1.1 \mathrm{~mm} \mathrm{~d}^{-1}$ ). The TSEB- $T_{C}-T_{S}$ version calculated daily $E T$ up to $1.6 \mathrm{~mm} \mathrm{~d}^{-1}(15 \%)$ less early in the season and up to $2.0 \mathrm{~mm} \mathrm{~d}^{-1}(44 \%)$ greater later in the season compared with lysimeter measurements. The TSEB- $T_{R}$ also calculated larger ET later in the season but only up to $1.4 \mathrm{~mm} \mathrm{~d}^{-1}(20 \%)$. ET underestimates by the TSEB- $T_{C}-T_{S}$ version may have been related to limitations in measuring $T_{C}$ early in the season when the canopy was sparse. ET overestimates later in the season by both versions may have been related to a greater proportion of non-transpiring canopy elements (flowers, bolls, and senesced leaves) being out of the $T_{C}$ and $T_{R}$ measurement view.
\end{abstract}

Published by Elsevier Ltd.

\footnotetext{
The US Department of Agriculture (USDA) prohibits discrimination in all its programs and activities on the basis of race, color, national origin, age, disability, and where applicable, sex, marital status, familial status, parental status, religion, sexual orientation, genetic information, political beliefs, reprisal, or because all or part of an individual's income is derived from any public assistance program. (Not all prohibited bases apply to all programs.) Persons with disabilities who require alternative means for communication of program information (Braille, large print, audiotape, etc.) should contact USDA's TARGET Center at (202) 720-2600 (voice and TDD). To file a complaint of discrimination, write to USDA, Director, Office of Civil Rights, 1400 Independence Avenue, S.W., Washington, D.C. 20250-9410, or call (800) 795-3272 (voice) or (202) 720-6382 (TDD). USDA is an equal opportunity provider and employer.

* Corresponding author. Address: USDA-ARS, P.O. Drawer 10, Bushland, TX 79012-0010, United States. Tel.: +1 806356 5763; fax: +1 8063565750.

E-mail address: Paul.Colaizzi@ARS.USDA.GOV (P.D. Colaizzi).
}

\section{Introduction}

Quantification and management of evapotranspiration (ET) and its components, evaporation $(E)$ and transpiration $(T)$, are some of several strategies being sought to increase crop water use efficiency (WUE, defined as economic yield per unit water used). In most cropping systems, $E$ is considered a loss because it does not contribute directly to biomass or yield production, but it may contribute to crop production indirectly if it can reduce $T$ by modifying the microclimate of the crop canopy [1]. Although $E$ may originate from either the soil or canopy surfaces (where the latter is from intercepted rain or irrigation water evaporating from the plant and not taken up by roots), the water storage capacity of the soil top layer (where $E$ occurs) is usually much greater compared with 
the canopy, hence most $E$ is considered to be from the soil. Therefore, considerable emphasis has been placed on investigating crop management strategies thought to influence soil $E$; examples include residue management $[2,3]$, crop row orientation, row spacing, plant spacing and population [4-6] and irrigation system comparison [7]. A number of studies have investigated the energy balance of the soil and canopy of row crops, which included measurements of $E$ (e.g. [2,3,8]) and $T$ (e.g. [1,6,9-12]) in addition to estimates to estimate $E T$. However, separate measurements of $E$ and $T$ entail much greater difficulty compared with ET ([13], 2012). Consequently, the impact of various management strategies on $E$ and $T$, and their partitioning in total $E T$, must often be inferred. This has limited the understanding of the physical processes involved, and has also likely limited our ability to exploit methods to increase WUE [14]. Even if $E$ and $T$ measurements were routinely available, it is well recognized that accurate simulation models are needed to supplement experimentation. Hence simulation models that calculate $E, T$, and $E T$, while not a substitute for field measurements, will have increasing impacts in finding practical ways to reduce $E$ and increase WUE.

Calculations of $E, T$, and $E T$ commonly use the gradient - resistance principle to model the energy exchange of the soil-plantatmosphere continuum, such as described by Shuttleworth and Wallace [15] and Shuttleworth and Gurney [16]. Several studies have applied the Shuttleworth and Wallace [15] approach to model the soil and canopy energy budgets separately (e.g. $[8,12,21,22]$ ); however, these often used detailed measurements of micrometeorological variables in the soil, canopy, and boundary layer space, which are not routinely available. Since radiometric surface temperature $\left(T_{R}\right)$ can be measured over areas at various spatial scales noninvasively, $T_{R}$ can be used as a convenient driver for remote sensing-based surface energy balance models where temperature is the primary gradient [17-19]. Most annual crops will contain partial canopy cover during the early part of the growing season, and possibly throughout the season. Therefore, $T_{R}$ is often a composite of canopy $\left(T_{C}\right)$ and soil $\left(T_{S}\right)$ component temperatures, especially for dryland or deficit-irrigated crops in non-humid regions where water is limited. Separate measurements of $T_{C}$ and $T_{S}$ are seldom available in practice. Although it may be possible to extract $T_{C}$ and $T_{S}$ from multiple view angles of $T_{R}$ [20], Chehbouni et al. [21] and Merlin and Chehbouni [22] showed that $T_{C}$ and $T_{S}$ retrievals are sensitive to errors in $T_{R}$ measurements, and more importantly, $T_{R}$ is usually available at only one view angle.

Norman et al. [23] described a two-source energy balance (TSEB) model (i.e., two-layer soil+canopy) where sensible $(H)$ and latent heat flux $(L E)$ for both the soil and canopy sources can be calculated separately using a single measurement of $T_{R}$ (i.e., one view angle), meteorological variables normally used to calculate ET (air temperature, vapor pressure deficit, wind speed, and solar irradiance), and ancillary information about the vegetation that is either readily available or can be reasonably estimated for common crops (leaf area index, crop height, row spacing, etc.). The $T_{R}, T_{C}$, and $T_{S}$ components are assumed related by simple linear mixing based on the Stephan-Boltzmann relationship between radiation and temperature:

$T_{R}^{4}=f_{V R} T_{C}^{4}+\left(1-f_{V R}\right) T_{S}^{4}$

where $f_{V R}$ is the fraction of vegetation appearing in the radiometer field of view (i.e., the vegetation view factor). With $T_{R}$ measured, an initial calculation of $T_{C}$ is made assuming non-water-stressed conditions, $T_{S}$ is calculated using Eq. (1), and the energy balance of the soil and canopy is calculated. If the calculated (non-waterstressed) $T_{C}$ does not result in a plausible energy balance closure (e.g., resulting in condensation on the soil during the daytime), $T_{C}$, $T_{S}$, and resistances are recalculated until a realistic energy balance is obtained; additional details are contained in the forthcoming section.

The Norman et al. [23] TSEB approach generally does not require any additional information beyond that required for simpler (single layer) energy balance models and can use a single measurement of $T_{R}$. Consequently, it and subsequent refinements [24-26] have been found practical for estimating surface energy fluxes for a wide variety of vegetation, vegetation cover, climates, and spatial scales where $T_{R}$ was obtained from ground-based, airborne, and satellite instruments. Studies included grass and desert shrubs near Tombstone, Arizona [23]; prairie grass near Manhattan, Kansas [23]; irrigated cotton near Maricopa, Arizona [23,27,28]; rangeland, pasture, and bare soil near El Reno, Oklahoma [29]; riparian zone along the Rio Grande in the Bosque Del Apache National Wildlife Refuge in Central New Mexico [29]; corn (Zea mays L.), soybean (Glycine max L.), and bare soil near Ames, Iowa [25,30]; and irrigated spring wheat (Triticum aestivum L.) near Maricopa, Arizona [31]. In addition, several studies compared the TSEB with single-layer or vegetation index - temperature approaches, with the TSEB generally giving the best agreement with $H$ and $L E$ estimates [32-35]. Most of these studies evaluated the TSEB model in terms of total (soil+canopy) $H, L E$, or $E T$, where calculated variables were compared to measurements using Bowen ratio, eddy covariance, or meteorological flux tower techniques. However, French et al. [31] derived ET from neutron probe measurements and a soil water balance, and Tang et al. [35] used large aperture scintillometers for independent estimates of turbulent fluxes.

Because of the paucity of separate $E$ and $T$ measurements, relatively few studies have considered how well the TSEB partitions these components, which may be prone to greater error compared with total $L E$ or $E T[24,36]$. Furthermore, relatively few studies included separate measurements of $T_{C}$ and $T_{S}$, which would allow more direct calculation of $E$ and $T$ without using the assumptions associated with Eq. (1) (described in more detail shortly), and which are otherwise used if only a single $T_{R}$ measurement is available. Sánchez et al. [37] tested a simplified version of the TSEB that used separate measurements of $T_{C}$ and $T_{S}$ for corn over a wide range of canopy cover; however, only flux tower estimates of total (soil+canopy) $H$ and $L E$ were available for that study. With accurate calculations of $E$ and $T$ urgently needed to evaluate techniques that impact WUE, a pertinent question is whether separate measurements of $T_{C}$ and $T_{S}$ would be advantageous over $T_{R}$, and if greater efforts should be directed accordingly.

In addition to the need to consider separate measurements of $E$, $T, T_{S}$, and $T_{C}$, relatively few studies have compared $E T$ calculated by the TSEB to ET measured by monolythic weighing lysimeters, or at locations having strong regional advection, such as the US Southern High Plains. Weighing lysimeters are presently the most accurate method to measure $E T$, and can be automated to provide nearly continuous measurements $[38,39]$. Although the Bowen ratio and eddy covariance measurement techniques have been widely used to evaluate the TSEB for their relative ease of deployment, they are known to suffer from measurement issues and assumptions, particularly when advection is present [40-42]. The neutron probe has been shown to be the most accurate method to measure soil water throughout the profile [43], and can estimate crop water use by calculating the soil water balance ([44], 2012). However, the neutron probe cannot be operated unattended because it is a radioactive device, and so cannot feasibly provide ET over hourly or shorter intervals or on larger spatial scales easily. Furthermore, the soil water balance may be subject to some uncertainty if deep percolation or runoff occur, but these can be minimized with irrigation management ([44], 2012).

The objectives of this paper are to compare measurements of $E$, $T$, and $E T$ with those calculated by the TSEB using (1) a single view angle measurement of $T_{R}$ (termed the TSEB- $T_{R}$ model version), and 
(2) separate measurements of $T_{C}$ and $T_{S}$ (termed the TSEB- $T_{C}-T_{S}$ model version). The $E, T$, and $E T$ measurements were obtained by microlysimeters, sap flow gauges, and weighing lysimeters, respectively, during a cotton season having a wide range of vegetation cover in a semiarid, advective location.

\section{Materials and methods}

\subsection{Two source energy balance model overview}

The TSEB model used in the current study was based on original formulations in Norman et al. [23] and Kustas and Norman [24], with subsequent modifications presented by Colaizzi et al. [45-47] and in Appendix A and B. Here we use the series resistance network form of the model to account for coupling between the soil and canopy (Fig. 1). As with most soil-plant-atmosphere energy balance algorithms, the TSEB considers the four major energy flux components, which are net radiation $\left(R_{N}\right)$, soil heat flux $(G)$, sensible heat flux $(H)$, and latent heat flux $(L E)$, and assume other energy components such as canopy heat storage and photosynthesis are negligible. The available energy is set equal to the turbulent fluxes:

$R_{N}-G=H+L E$

where turbulent fluxes are positive away from the canopy. In the TSEB, $R_{N}, H$, and $L E$ are further partitioned to their canopy and soil components, and the energy balance is expressed as

$L E_{C}=R_{N, C}-H_{C}$

$L E_{S}=R_{N . S}-G-H_{S}$

where the subscripts $C$ and $S$ refer to the canopy and soil, respectively. $R_{N, C}$ and $R_{N, S}$ were calculated by combining the radiative transfer model of Campbell and Norman [48], which calculates the photosynthetic, near-infrared, direct beam, diffuse, and long wave components separately, with modifications described in Colaizzi et al. [46,47]. Briefly, these modifications included developing geometric view factors to account for the non-random spatial distribution of row crop vegetation, and optimizing the ellipsoidal leaf angle distribution function parameter and leaf visible and near infrared absorption parameters for cotton. Equations to calculate $R_{N, C}$ and $R_{N, S}$ are given in Appendix A.

Previous TSEB studies have usually estimated $G$ as a constant fraction of $R_{N, S}$; however, $G$ often has a strong phase difference with $R_{N, S}$, which was observed at our location during the daytime when $R_{N, S}>0$. Therefore, daytime $G$ was calculated using a phase difference equation described by Santanello and Friedl [49], and nighttime $G$ was calculated as a constant fraction of $R_{N, S}$ :

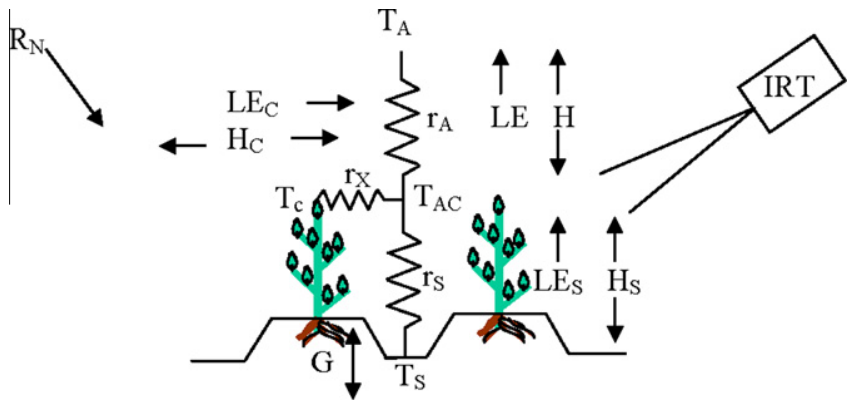

Fig. 1. Series resistances and flux components for the two source energy balance model, adopted from Norman et al. [23], Fig. 11. See text for symbol definitions.
$G_{D A Y}=R_{N, S}\left\{a \cdot \cos \left[\frac{2 \pi}{b}(t+c)\right]\right\}, \quad R_{N, S}>0$

$G_{N I G H T}=d R_{N, S}, \quad R_{N, S} \leqslant 0$

where $t$ is the solar time angle (seconds), $a$ is the amplitude parameter, $b$ is the period, and $c$ is the phase shift. In the present study, $a=0.15, b=86,400 \mathrm{~s}$ (i.e., $24 \mathrm{~h}$ ), $c=10,800 \mathrm{~s}$ (i.e., $3 \mathrm{~h}$ ), and $d=0.5$ were derived by minimizing the discrepancy between calculated $G$ and surface $G$ derived from heat flux plates and temperature measured below the surface [50]. A more exhaustive study on soil heat flux models is presently underway using field measurements at our location.

$H$ is calculated by temperature gradient-transport resistance networks between the soil, canopy, and air above (Fig. 1). Two alternate network formulations were proposed by Norman et al. [23], describing a parallel and a series resistance framework. In the parallel network (not shown), turbulent fluxes occur as separate (parallel) streams between the soil or canopy and atmosphere, and there is no direct interaction between the soil and canopy. $\mathrm{Li}$ et al. [30] reported that the parallel model was more sensitive to errors in vegetation cover estimates, and that these uncertainties may be moderated by the additional parameter of within-canopy air temperature that is used in the series formulation $\left(T_{A C}\right.$ in Fig. 1). Kustas and Norman [24], Kustas et al. [51], and Li et al. [30] concluded that the series was preferable over the parallel model for heterogeneous landscapes containing a large range of vegetation cover, which was the case in the current study. In addition, a number of studies have documented significant turbulent exchange between the soil and canopy, which would be accounted for by the series formulation (e.g. $[9,11,12])$. In Fig. 1, sensible heat flux for the canopy $\left(H_{C}\right)$, soil $\left(H_{S}\right)$, and total $(H)$ are calculated as:

$H_{C}=\rho C_{P} \frac{T_{C}-T_{A C}}{r_{X}}$

$H_{S}=\rho C_{P} \frac{T_{S}-T_{A C}}{r_{S}}$

$H=\rho C_{P} \frac{T_{A C}-T_{A}}{r_{A}}$

where $\rho$ is the air density $\left(\mathrm{kg} \mathrm{m}^{-3}\right), C_{P}$ is the specific heat of air (assumed constant at $\left.1013 \mathrm{~J} \mathrm{~kg}^{-1} \mathrm{~K}^{-1}\right), T_{C}, T_{A}, T_{S}$, and $T_{A C}$ are the temperatures of the canopy, air, soil, and air temperature within the canopy boundary layer, respectively $(\mathrm{K}), r_{X}$ is the resistance in the boundary layer near the canopy $\left(\mathrm{s} \mathrm{m}^{-1}\right), r_{S}$ is the resistance to heat flux in the boundary layer immediately above the soil surface ( $\mathrm{s}$ $\left.\mathrm{m}^{-1}\right)$, and $r_{A}$ is the aerodynamic resistance $\left(\mathrm{s} \mathrm{m}^{-1}\right) \cdot r_{X}$ was calculated according to Norman et al. [23] and $r_{S}$ and $r_{A}$ were calculated according to Kustas and Norman [24].

The current study evaluated two model versions of the TSEB: one using a single view angle measurement of the composite directional radiometric surface temperature $\left(T_{R}\right.$; termed the TSEB- $T_{R}$ version), and second version using separate measurements of $T_{C}$ and $T_{S}$ (termed the TSEB- $T_{C}-T_{S}$ version). Operationally, $T_{S}$ and $T_{C}$ are seldom available (even in small-scale ground-based applications; [52]), and must be calculated from the composite directional radiometric surface temperature $\left(T_{R}\right)$. In the TSEB- $T_{R}$ version, $T_{R}$ is related to $T_{C}$ and $T_{S}$ in Eq. (1). Because Eq. (1) has two unknowns $\left(T_{S}\right.$ and $\left.T_{C}\right)$, the TSEB- $T_{R}$ version calculates an initial estimate of $T_{C}$ and solves for $T_{S}$. Initial calculations of $T_{C}$ have usually used a form of the Priestley-Taylor equation [53], which is supported by Norman et al. [23], Kustas and Anderson [26], and Agam et al. [54]:

$T_{C I}=T_{A}+\frac{R_{N, C} r_{A}}{\rho C_{P}}\left[1-\alpha_{P T} f_{G} \frac{\Delta}{\Delta+\gamma}\right]$ 
where $T_{C I}$ is the initial estimate of $T_{C}, \alpha_{P T}$ is the Priestley-Taylor parameter $\left(\alpha_{P T} \sim 1.3\right), f_{G}$ is the fraction of green vegetation, $\Delta$ is the slope of the saturation vapor pressure - temperature relation $\left(\mathrm{kPa}{ }^{\circ} \mathrm{C}^{-1}\right), \gamma$ is the psychrometric constant $\left(\mathrm{kPa}{ }^{\circ} \mathrm{C}^{-1}\right)$, and other terms are as defined previously. Then the temperature gradient resistance system of equations is solved using an iterative secant method procedure described in Norman et al. [23], and $T_{C}$ and $T_{S}$ are recalculated until energy balance closure is reached. In the case of water-stressed vegetation, non-transpiring canopy elements (e.g., senesced leaves or non-leaf elements), or small vapor pressure deficit ( $<1 \mathrm{kPa}$ ), $T_{C I}$ may be underestimated, resulting in overestimates of $T_{S}$ and $H_{S}$, and possibly resulting in $L E_{S}<0$ (from Eq. 1(b)). This would imply condensation at the soil surface, which is unlikely during daytime hours in non-humid climates. Therefore, if the model solution resulted in $L E_{S}<0$, then $\alpha_{P T}$ is reduced incrementally (resulting in increased $T_{C I}$ in Eq. 6) until $L E_{S} \geqslant 0$. For a completely dry soil surface, it is possible that the resulting $L E_{S}$ could still be negative even though $\alpha_{P T}=0$, which in this case $L E_{S}$ is set to zero, and from Eq. $3 \mathrm{~b}, H_{S}=R_{N, S^{-}} G$, and the remaining energy flux components are recalculated according to these constraints.

In the current study, the TSEB- $T_{R}$ version was run according to the iterative procedure described above, except that calculation of $T_{C I}$ and subsequent iterations used a formulation for canopy transpiration based on the non-water-stressed form of the Penman-Monteith equation, similar to Jackson et al. [55]:

$T_{C I}=T_{A}+\frac{R_{N, C} r_{A} \gamma^{*}}{\rho C_{P}\left(\Delta+\gamma^{*}\right)}-\frac{e_{S}-e_{A}}{\Delta+\gamma^{*}}$

where $\gamma_{*}=\gamma\left(1+r_{C} / r_{A}\right), r_{C}$ is the bulk canopy resistance $\left(\mathrm{s} \mathrm{m}^{-1}\right), e_{S}$ and $e_{A}$ are the saturation and actual vapor pressures of the air, respectively $(\mathrm{kPa})$, and all other terms are as defined previously. We used $r_{C}=50 \mathrm{~s} \mathrm{~m}^{-1}$ during the daytime $\left(R_{N}>0 \mathrm{~W} \mathrm{~m}^{-2}\right)$ and $r_{C}$ $=200 \mathrm{~s} \mathrm{~m}^{-1}$ during the night time $\left(R_{N} \leqslant 0 \mathrm{~W} \mathrm{~m}^{-2}\right)$; the rationale and a thorough discussion for these $r_{C}$ values are given in Allen et al. [56]. Analogous to incrementally decreasing $\alpha_{P T}$ when $L E_{S}<$ 0 as described above, daytime $r_{C}$ was increased in increments of $10 \mathrm{~s} \mathrm{~m}^{-1}$, up to $1000 \mathrm{~s} \mathrm{~m}^{-1}$ until $L E_{S} \geqslant 0$. (The upper limit of $1000 \mathrm{~s} \mathrm{~m}^{-1}$ was chosen arbitrarily; different values did not change TSEB- $T_{R}$ results).

The justification for using the Penman-Monteith (Equation (7)) in place of the Priestley-Taylor (Equation (6)) equation is as follows. The influence of vapor pressure deficit $\left(V P D=e_{S}-e_{A}\right)$ is accounted for in the $\alpha_{P T}$ term, which is usually assumed constant unless negative $L E_{S}$ requires it to be reduced. In the current dataset, $\sim 90 \%$ of the VPD measurements were below $3.5 \mathrm{kPa}$, but VPD did reach as large as $5.5 \mathrm{kPa}$ during sunny, warm, advective afternoons ([13], 2012). Preliminary results in the current study, as well as those in Kustas et al. ([57], 2012), indicated that the Priestley-Taylor approximation for $T_{C I}$, where $\alpha_{P T}=1.3$, resulted in reasonable agreement between measured and calculated total $L E$, even for large $V P D$. However, a preliminary analysis using the sap flow and microlysimeter measurements of $E$ and $T$ from Agam et al. ([13], 2012) indicated that transpiration $(T)$ tended to be underestimated, implying that $T_{C I}$ was overestimated in Eq. (6), and solution of the temperature gradient - resistance system of equations resulted in soil evaporation $(E)$ being overestimated. Hence, while the Priestley- Taylor approximation provided reasonable calculations of total $L E$, it incorrectly partitioned $L E_{S}$ and $L E_{C}$ under conditions of large VPD. A detailed comparison and analysis of the Priestley-Taylor versus Penman-Monteith algorithms employed in the TSEB- $T_{R}$ model was beyond the scope of the current study, but this will be addressed in a forthcoming paper. Substitution of the Priestley-Taylor with the Penman-Monteith equation required modification of the original Norman et al. [23] secant procedure, as described in Appendix B.
An additional modification to the TSEB used in the current study warrants mention. The fraction of vegetation appearing in the radiometer field-of-view ( $f_{V R}$ in Eq. (1)) is calculated using a model developed by Colaizzi et al. [45] that explicitly accounts for the circular or elliptical footprint of the IRT. Using digital photographs, this approach was shown to reduce errors in $f_{V R}$ calculations by $15 \%$ compared with the commonly used clumping index approach [25], which was developed for square or rectangular pixels and is therefore less suitable for circular or elliptical footprints. In Eq. $(1), f_{V R}$ never physically exceeds 1.0 because of canopy extinction, and this constraint would be required in any case in order to solve for $T_{S}$. If $f_{V R}$ is close to 1.0, $T_{S}$ can be sensitive to small errors in $T_{C}$ or $f_{V R}$, resulting in unrealistic values. Therefore, in this implementation, $T_{S}$ was constrained from falling below the air wet bulb temperature $\left(T_{W}\right)$, which represents the lower limit for an evaporating surface [58]. $T_{W}$ was calculated by solving the relation $e_{A}=e_{S}\left[T_{W}\right]-\gamma_{P S Y}\left(T_{A}-T_{W}\right)$ using the Newton-Raphson method, where $\gamma_{P S Y}=6.62 \times 10^{-4} P_{A}$ for ventilated psychrometers, $P_{A}$ is the atmospheric pressure, and $P_{A}=88.21 \mathrm{kPa}$ for $1170 \mathrm{~m}$ above MSL at the study location [59].

Calculated $L E_{S}, L E_{C}$, and $L E$ were converted to soil evaporation $(E)$, plant transpiration $(T)$, and evapotranspiration (ET), respectively, by multiplying by the time step (15-min or $900 \mathrm{~s}$ in the current study) and dividing by the latent heat of vaporization $(\lambda)$, where $\lambda=2.501-0.002361 T_{A}$, and $\lambda$ is in $\mathrm{MJ} \mathrm{kg}^{-1}$ and $T_{A}$ is air temperature in ${ }^{\circ} \mathrm{C}$, and assuming the density of water is constant at $1000 \mathrm{~kg}^{-3}$. Daytime $\lambda$ was typically $2.44 \mathrm{MJ} \mathrm{kg}^{-1}$ at the study location. Daily ET was calculated by summing $15-\mathrm{min} E T$ to $24 \mathrm{~h}$ totals. Since $E$ was measured by microlysimeter at dawn and dusk, and $T$ was measured by the heat pulse method from 7:00 to 22:00 CST, the calculated 15-min $E$ and $T$ were summed to the measured time intervals.

\subsection{Field measurements}

All field measurements used in this study were obtained at the USDA-ARS Conservation and Production Research Laboratory, Bushland, Texas, USA ( $35^{\circ} 11^{\prime} \mathrm{N}$ lat., $-102^{\circ} 06^{\prime} \mathrm{W}$ long., $1170 \mathrm{~m}$ elevation M.S.L.). Additional details of the study location, instrumentation, and procedures used in the BEAREX08 field campaign are described in Evett et al. ([44], 2012) and Agam et al. ([13], 2012), but a summary is given here. The climate is semi-arid with a large evaporative demand of about $2600 \mathrm{~mm}$ per year (Class A pan evaporation) and precipitation averaging $470 \mathrm{~mm}$ per year. Strong advection of heat energy from the south and southwest is typical, with $\mathrm{H}$ having been reported to contribute up to $60 \%$ of total LE for fully irrigated alfalfa [60]. The soil is a Pullman clay loam (fine, mixed, super active, thermic torrertic Paleustolls) with slow permeability, having a dense B2 layer from about $0.15-$ to $0.40-\mathrm{m}$ depth and a calcic horizon that begins at the 1.1-m depth [61]. $E T, E$, and $T$ were measured, respectively, with a large monolithic weighing lysimeter, microlysimeters, and sap flow gauges ([13], 2012). For comparison with calculated $L E$, measured ET was converted to $L E$ by multiplying by $\lambda$ and dividing by the time step (900 s).

Upland cotton (Gossypium hirsutum L.) was seeded on 17 May 2008 (DOY 142) with a plant density of 15.8 seeds $\mathrm{m}^{-2}$ ) on raised beds oriented north-south and spaced $0.76 \mathrm{~m}$ apart. Cultural practices were similar to those used for large-yield production in the Southern High Plains. Irrigation was applied with a hose-fed lateral move sprinkler system to fully meet crop ET demand. Furrow dikes were installed across raised beds following crop establishment to control runoff and run on of irrigation and rainfall [62].

Four monolythic lysimeters were each located in the centers of four $\sim 4.7$ ha fields arranged in a square pattern. Each lysimeter and field were designated as northeast (NE), southeast (SE), northwest 
(NW) and southwest (SW); the present study including lysimeter measurements were conducted in the NE field. Each lysimeter had a surface area of $9.0 \mathrm{~m}^{2}(3.0 \mathrm{~m} \times 3.0 \mathrm{~m})$ and was $2.4 \mathrm{~m}$ deep [38,39], calibrated to an accuracy of $0.04 \mathrm{~mm}$ in January 2008 ([44], 2012). ET was determined by the net change in lysimeter mass divided by the lysimeter area, which included losses (evaporation and transpiration) and gains (irrigation, precipitation, dew). Lysimeter mass was measured using a load cell (model SM-50, Interface ${ }^{1}$ Scottsdale, Arizona) and cantilever system, reported as 15-min averages. Drainage from the lysimeter was maintained with a $-10 \mathrm{kPa}$ vacuum pump system, and the drainage effluent was stored in two tanks suspended by separate load cells from the lysimeter. Data were not used during days when irrigation, precipitation, plant measurements, or instrument maintenance and repair occurred.

The microlysimeters used to measure $E$ were deployed approximately $30 \mathrm{~m}$ northeast of the lysimeter (at a location termed the Primary site in the BEAREX study) in two replicates of 5 each across two interrows, and spaced $0.075,0.225,0.375,0.525$, and $0.675 \mathrm{~m}$ west to east. The microlysimeter walls were constructed of white polyvinyl chloride, $105-\mathrm{mm}$ inside diameter, 8-mm thick, with metal bottoms. The wall material minimized lateral heat transfer, and the metal bottoms minimized impedance to vertical heat transfer ([13], 2012). The microlysimeters were weighed manually using a scale (precision equivalent to $0.01 \mathrm{~mm}$ of water) around dawn and dusk in an enclosed box to avoid being influenced by wind. The sap flow gauges (models SGA-5 and SGA-9, Dynamax, Inc. Houston, TX) used to measure $T$ were deployed approximately $30 \mathrm{~m}$ north of the lysimeter and $20 \mathrm{~m}$ west of the Primary site on 10 plants. The gauges were installed on the plant stems about $0.05 \mathrm{~m}$ above the soil surface and below the first plant nodes. The gauges were the heat balance type where about $0.1 \mathrm{~W}$ was applied to heat the gauge strips and were shielded with insulation and aluminum foil to avoid external heating. Measurements were sampled every $5 \mathrm{~s}$ and averaged to 30-min from 7:00 to 22:00 CST. Additional information on the microlysimeters and sap flow gauges are in Agam et al. ([13], 2012) and references therein.

Directional brightness temperature $\left(T_{B}\right)$ was measured using Exergen infrared thermometers (IRTs) (model IRT/c, Exergen Corp., Watertown, Massachusetts, USA) with a 5:1 field of view and 8$14 \mu \mathrm{m}$ band width. The IRTs were deployed at the Primary site ( $\sim 30 \mathrm{~m}$ from the lysimeter) near the measurement sites of $E$ and $T$. Each IRT was stationary, and insulated from the outside air to reduce the influence of longwave radiation variability from the internal body cavity on the detector. All $T_{B}$ were converted to radiometric temperature by subtracting the reflected atmospheric longwave radiation from the contribution to $T_{B}$ [63]. Longwave reflectance was assumed equal to the complement of the bulk (soil and canopy) surface emittance, which was assumed $=0.98$ (i.e., longwave reflectance $=1.0-0.98$ ). Soil emittance equal to 0.98 was verified by measurements over bare soil using a Cimel CE 312 multiband thermal radiometer (Cimel Electronique, Paris, France), and canopy emittance equal to 0.98 was assumed based on Idso et al. [64] and Campbell and Norman [48]. Atmospheric emittance was calculated using the Idso [65] equation. $T_{R}$ was measured by two IRTs deployed $1.5 \mathrm{~m}$ above the center of the crop row with a nadir view, resulting in a circular footprint approximately $0.30 \mathrm{~m}$ in diameter at the soil surface. $T_{S}$ was measured by 12 IRTs deployed $0.30 \mathrm{~m}$ above the soil surface at the interrow center with a zenith view angle of $45^{\circ}$, resulting in an elliptical footprint with major and minor axes approximately 0.085 and $0.06 \mathrm{~m}$, respectively, at the soil surface, where the minor axis $(0.06 \mathrm{~m})$ was

\footnotetext{
${ }^{1}$ The mention of trade names of commercial products in this article is solely for the purpose of providing specific information and does not imply recommendation or endorsement by the US Department of Agriculture.
}

perpendicular to the crop rows [45]. $T_{C}$ was measured by 12 IRTs deployed at $2 / 3$ of the canopy height in the crop rows with nearhorizontal view angles. The IRTs used to measure $T_{S}$ and $T_{C}$ were pointed parallel to the crop row, with 6 pointed south and 6 pointed north. All IRT lenses were cleaned each morning and inspected for correct viewing angle using a laser jig that was machined to fit into the lens barrel. The times of cleaning and view inspection were noted and IRT measurements were excluded from the data. Measurements from IRTs were excluded if measurements deviated more than $1^{\circ} \mathrm{C}$ from the average IRT temperature [66].

Meteorological variables required by the TSEB model include incoming solar irradiance $\left(R_{S}\right)$, air temperature $\left(T_{A}\right)$, relative humidity $(R H)$, and wind speed $(U)$. $R_{S}$ was measured by a pyranometer (model PSP, Eppley Laboratories, Inc., Newport, Rhode Island) at a grass reference site $\sim 250 \mathrm{~m}$ east of the lysimeter. $T_{A}, R H$, and $U$ were measured at 2-m above the soil surface from an instrumented mast immediately north of the lysimeter. $T_{A}$ and $R H$ were measured by instruments in a radiation shield (model HMP45C, Vaisala, Inc., Helsinki, Finland), and $U$ was measured by a cup anemometer (model Wind Sentry 03101-5, R.M. Young Co., Traverse City, Michigan). All meteorological variables were subject to quality inspection following the procedures in Allen et al. [59]. In addition, soil heat flux was measured at the lysimeter by four plates (model HFT-1, Radiation and Energy Balance Systems, Inc., Seattle, Washington) buried $50 \mathrm{~mm}$ below the surface. Soil heat flux at the surface $(G)$ was calculated using a soil water balance equation and measurements of soil temperature with thermocouples (model TMTSS-125G, Omega Engineering, Inc., Stamford, Connecticut) buried 10 and $40 \mathrm{~mm}$ below the surface at four locations near each soil heat flux plate [50]. There were a total of four heat flux plate thermocouple sets, with two located beneath adjacent crop rows and two located beneath adjacent interrows. Surface $G$ (derived from flux plate and temperature measurements), as well as $E, T$, $L E$, and $E T$ were compared with $G$ calculated by the TSEB- $T_{R}$ and TSEB- $T_{C}-T_{S}$ model versions.

Plant measurements and samples were taken periodically at key growth stages at three $1.0 \mathrm{~m}^{2}$ sites in the lysimeter field. Leaf area was measured with a Li-COR leaf area meter (model Li-3100, Lincoln, Nebraska), and the meter accuracy was verified periodically with a $0.005 \mathrm{~m}^{2}$ standard disk. Plant width $\left(w_{C}\right)$ and plant height $\left(h_{C}\right)$ were measured at the leaf area sample sites prior to plant sampling, and also at the lysimeter and at the IRT location; $w_{C}, h_{C}$, and leaf area index ( $L A I$, calculated from leaf area measurements) were related to growing degree days by linear interpolation so that these parameters could be estimated between sample dates.

\subsection{Model evaluation}

Agreement between calculated and measured $R_{N}, G, L E, E T, E$, and $T$ were compared in terms of the first-order (i.e., non-squared) index of agreement $(I O A)$, root mean squared error (RMSE), mean absolute error $(M A E)$, and mean bias error $(M B E)$, and the error variables were also reported as a percentage of measured means. The $I O A$ varies from $-\infty$ to 1.0 , with greater $I O A$ indicating better model agreement, and the first-order IOA described by Legates and McCabe [67] was chosen because it is less sensitive to outliers compared with squared or larger order IOA. The extent that RMSE>$M A E$ is related to the presence of outliers in the data [67].

\section{Results and discussion}

\subsection{Vegetation cover}

During the period of rapid crop development (from around DOY 200 to 260$), w_{C}$ and $h_{C}$ were larger at the NE lysimeter and Primary 

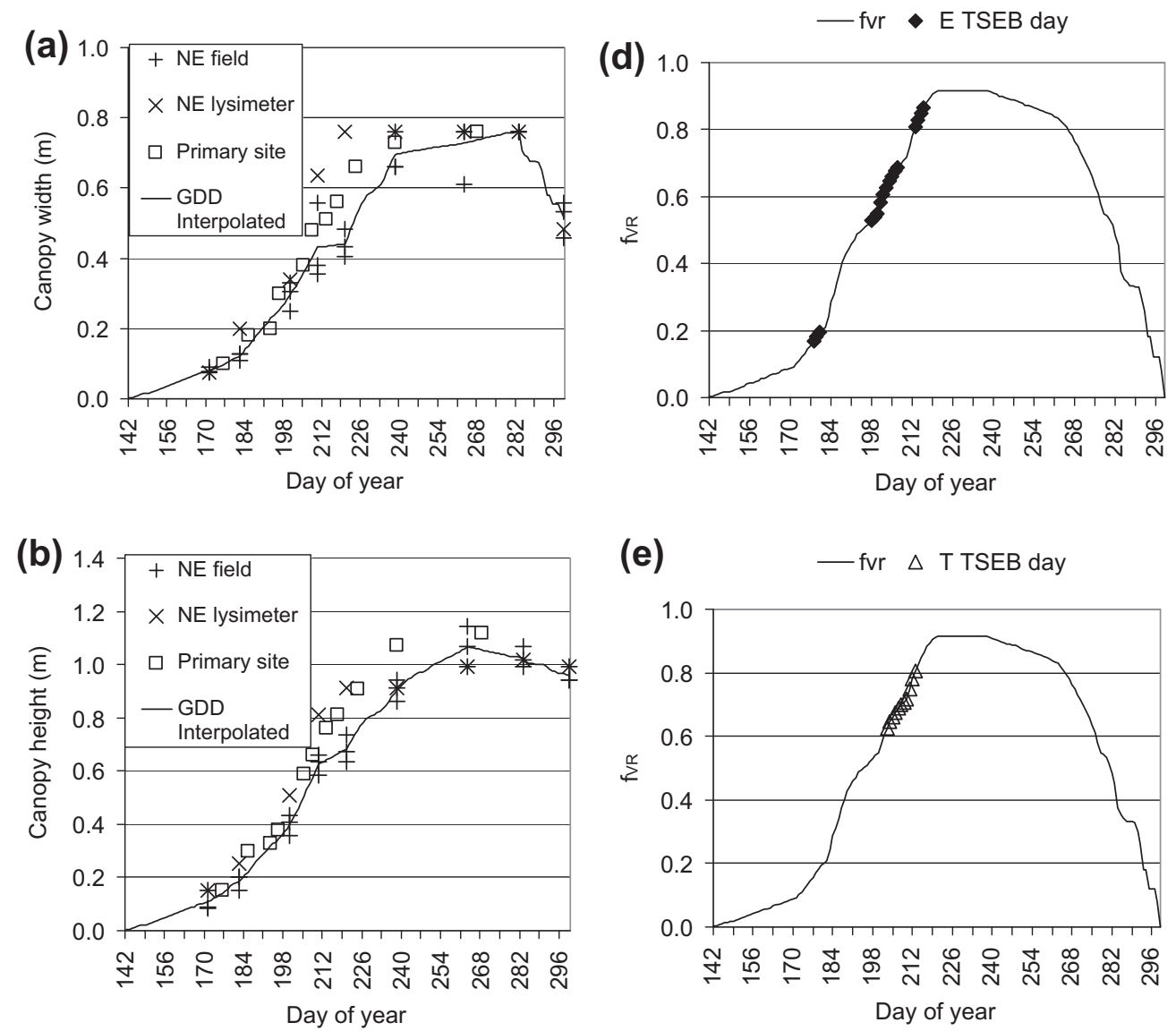

(e)

- fvr $\triangle$ T TSEB day

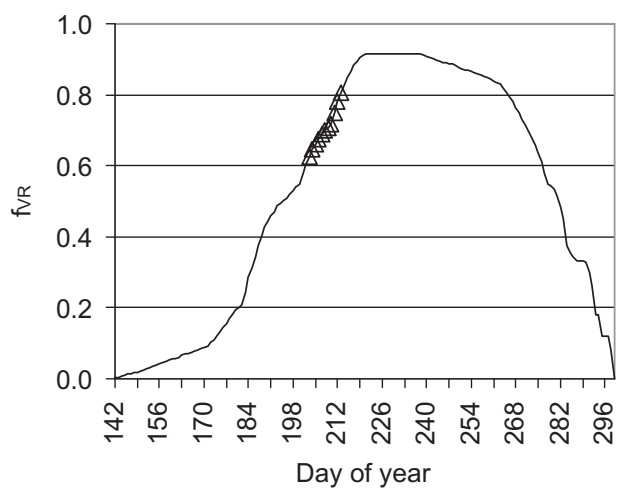

(f) $\quad$ fvr + ET TSEB day

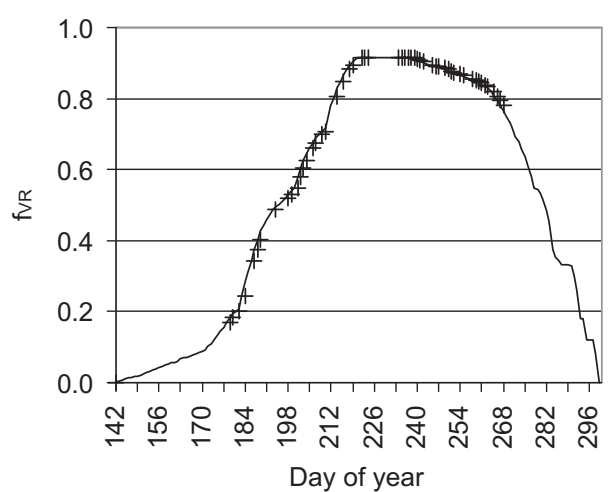

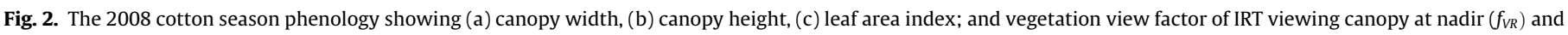
days of TSEB model evaluation when measured (d) E, (e) $T$, and (f) ET were compared with calculated values.

Site compared with sites in the NE field where destructive plant samples were obtained for LAI measurements (Fig. 2(a)-(c)). This, along with the findings of Alfieri et al. ([42], this issue) and Evett et al. ([44], 2012) that lysimeter ET was greater compared with the field average, implied that $L A I$ at the lysimeter and Primary site were also larger during this period compared with the field average. Some differences in $w_{C}$ and $h_{C}$ were apparent between the lysimeter and the Primary site; therefore, at least some discrepancy between the models and measurements was likely related to local spatial variability between the lysimeter (where ET was measured) and the Primary site (where $T_{C}, T_{S}, T_{R}$, and $E$ were measured), as well as west of the Primary site (where $T$ was measured). The seasonal trend of $f_{V R}$ (Fig. 2 (d)-(f)) was similar to seasonal trends of $w c, h c$, and $L A I$, which was expected because the $f_{V R}$ model is a function of plant phenology [45]. Measurements of $E$ and $E T$ that were valid for TSEB model evaluation (i.e., no interference from precipitation, irrigation, or instrument maintenance) were obtained over a wide range of vegetation cover and $f_{V R}$, where $0.17 \leqslant f_{V R} \leqslant 0.86$ for $E$, and $0.17 \leqslant f_{V R} \leqslant 0.92$ for ET. Measurements of $E$ were obtained during crop development before $f_{V R}$ reached a seasonal maximum (i.e., when $L A I$ peaked) during the intensive observation periods described in Agam et al. ([13], 2012). Measurements of ET were obtained from the early part of the season through the beginning of leaf senescence when $f_{V R}$ declined to 0.78 as LAI began to decrease. However, $T$ measurements were obtained only from DOY 203 to 213 , when $0.60<f_{V R}<0.81$, and only 
during the daytime. As noted in Agam et al. ([13], 2012), simultaneous measurements of $E$ and $T$ were obtained on only four days without interference from precipitation or irrigation events, and only two of these days occurred when ET was measured without interference from maintenance of the lysimeter instruments. Therefore, data were insufficient to evaluate the TSEB model by comparing calculated and measured $E+T=E T$ on the same days. Nonetheless, comparison of calculated vs. measured $E$ (night and day) and $T$ (day only) was possible on days when valid measurements were obtained.

\subsection{Calculated vs. measured variable agreement}

Agreement between calculated and measured $R_{N}$ was similar using the TSEB- $T_{R}$ and TSEB- $T_{C}-T_{S}$ model versions, with the latter version resulting in slightly greater scatter compared with the former (Fig. 3). The TSEB- $T_{R}$ version resulted in IOA $=0.92$ and RMSE, $M A E$, and $M B E$ of 28,22 , and $-1.5 \mathrm{~W} \mathrm{~m}^{-2}$ ), respectively (Table 1 ). The TSEB- $T_{C}-T_{S}$ also resulted in $I O A=0.92$ and respective $R M S E$, $M A E$, and $M B E$ of 30,23 , and $-1.6 \mathrm{~W} \mathrm{~m}^{-2}$ ) (Table 2). The $M A E$ in the current study were greater and $M B E$ were similar compared with those reported by Kustas et al. ([57], 2012), where $M A E=15$
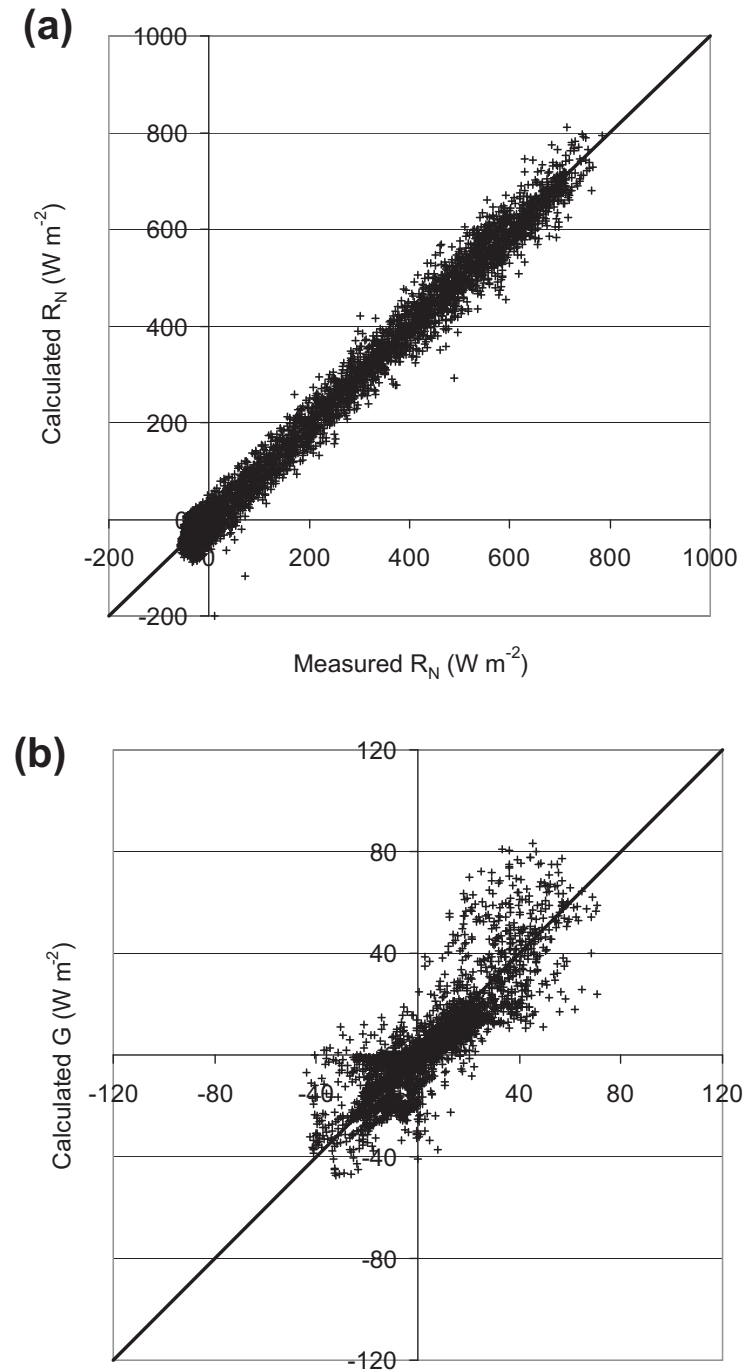

Measurement-derived $\mathrm{G}\left(\mathrm{W} \mathrm{m}^{-2}\right)$ and $M B E=2 \mathrm{~W} \mathrm{~m}^{-2}$ ); however, the current study also included nighttime data.

Calculated $G$ using the TSEB was compared with surface $G$ derived from flux plate and temperature measurements (Fig. 3). Here, $G$ was calculated using both the TSEB- $T_{R}$ and TSEB- $T_{C}-T_{S}$ model versions. The TSEB- $T_{R}$ version resulted in calculated vs. measurement-derived $I O A=0.71$ and $R M S E, M A E$, and $M B E$ of 9.6, 6.9, and $0.9 \mathrm{~W} \mathrm{~m}^{-2}$ ), respectively (Table 1 ). The TSEB- $T_{C}-T_{S}$ version resulted in similar agreement, with $I O A=0.74$ and respective $R M S E, M A E$, and $M B E$ of $9.3,6.5$, and $-2.0 \mathrm{~W} \mathrm{~m}^{-2}$ ) (Table 2). The relatively small RMSE, MAE, and MBE were the result of using both daytime and nighttime G; these discrepancies would have been on the order of $\sim 40 \mathrm{~W} \mathrm{~m}^{-2}$ ) if only daytime calculated and measurementderived $G$ were compared, as reported by Kustas et al. ([57], 2012). Since $G$ is formulated as a function of $R_{N, S}$, the small differences in each model version of $G$ were the result of differences in the net longwave component in $R_{N, S}$, which was calculated using $T_{C}$ and $T_{S}$ (i.e., either measured directly or calculated from $T_{R}$ ).

The largest differences between calculated and measurementderived $G$ (i.e., largest scatter in Fig. 3) occurred when $G>\sim 20$ $\mathrm{W} \mathrm{m}^{-2}$ ). This occurred early in the season, when canopy cover was sparse, and within 1-2 h of solar noon. Since the crop rows
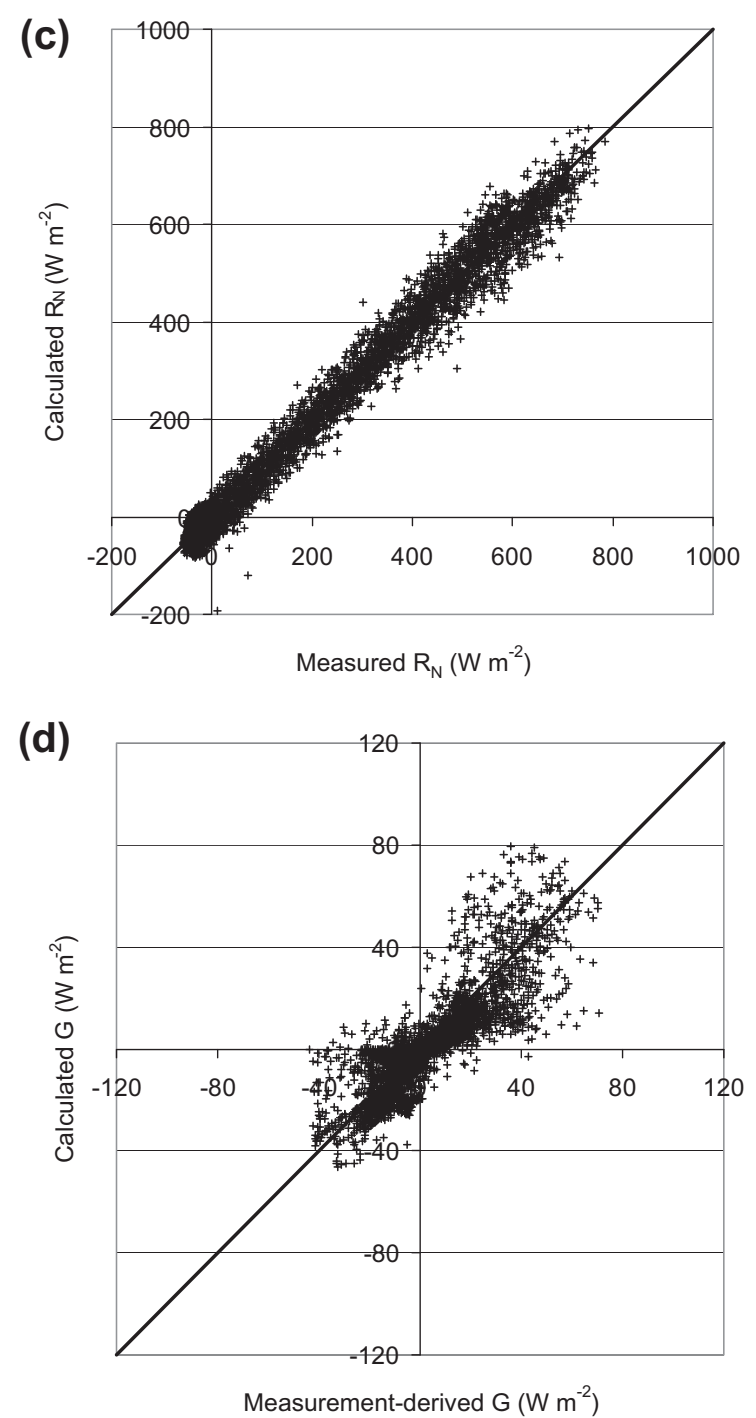

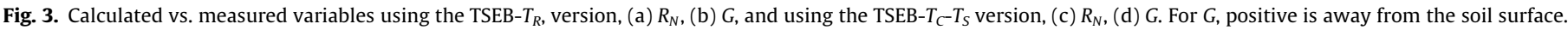
See Tables 1 and 2 for statistical parameters of agreement 
Table 1

Statistical parameters of agreement for calculated vs. measured variables using the TSEB- $T_{R}$ version. See Fig. 3(a) and (b), 4(a)-(c) for scatter plots.

\begin{tabular}{|c|c|c|c|c|c|c|}
\hline & $R_{N}\left(\mathrm{~W} \mathrm{~m}^{-2}\right)$ & $G\left(\mathrm{~W} \mathrm{~m}^{-2}\right)$ & $L E\left(\mathrm{~W} \mathrm{~m}^{-2}\right)$ & $E T\left(\mathrm{~mm} \mathrm{~d}^{-1}\right)$ & $E(\mathrm{~mm})$ & $T(\mathrm{~mm})^{\mathrm{a}}$ \\
\hline$n=$ & 5949 & 4961 & 5086 & 53 & 22 & 11 \\
\hline Measured average & 166 & 0.6 & 203 & 7.2 & 0.94 & 6.9 \\
\hline Measured $S D$ & 243 & 17 & 231 & 2.3 & 0.90 & 1.0 \\
\hline Calculated average & 165 & 1.4 & 208 & 7.4 & 0.95 & 7.0 \\
\hline Calculated $S D$ & 242 & 17 & 244 & 2.3 & 1.4 & 1.0 \\
\hline$I O A$ & 0.92 & 0.71 & 0.88 & 0.86 & 0.71 & 0.50 \\
\hline RMSE & 28 & 9.6 & 67 & 0.6 & 0.7 & 0.9 \\
\hline \% RMSE & $17 \%$ & & $33 \%$ & $8.7 \%$ & $78 \%$ & $13 \%$ \\
\hline$M A E$ & 22 & 6.9 & 47 & 0.5 & 0.6 & 0.8 \\
\hline$\% M A E$ & $13 \%$ & & $23 \%$ & $6.8 \%$ & $63 \%$ & $11 \%$ \\
\hline$M B E$ & -1.5 & 0.9 & 5.4 & 0.2 & 0.01 & 0.1 \\
\hline$\% M B E$ & $-0.9 \%$ & & $2.7 \%$ & $2.6 \%$ & $0.94 \%$ & $1.3 \%$ \\
\hline
\end{tabular}

a From 0700 to 2200 CST.

Table 2

Statistical parameters of agreement for calculated vs. measured variables using the TSEB- $T_{C}-T_{S}$ version. See Figs. 3(c) and (d), 4(d)-(f) for scatter plots.

\begin{tabular}{|c|c|c|c|c|c|c|}
\hline & $R_{N}\left(\mathrm{~W} \mathrm{~m}^{-2}\right)$ & $G\left(\mathrm{~W} \mathrm{~m}^{-2}\right)$ & $L E\left(\mathrm{~W} \mathrm{~m}^{-2}\right)$ & $E T\left(\mathrm{~mm} \mathrm{~d}^{-1}\right)$ & $E(\mathrm{~mm})$ & $T(\mathrm{~mm})^{\mathrm{a}}$ \\
\hline$n=$ & 5949 & 4961 & 5086 & 53 & 22 & 11 \\
\hline Measured average & 166 & 0.6 & 203 & 7.2 & 0.9 & 6.9 \\
\hline Measured SD & 243 & 17 & 231 & 2.3 & 0.9 & 1.0 \\
\hline Calculated average & 165 & -1.4 & 200 & 7.1 & 1.2 & 5.5 \\
\hline Calculated $S D$ & 242 & 17 & 249 & 2.1 & 1.5 & 0.8 \\
\hline$I O A$ & 0.92 & 0.74 & 0.85 & 0.71 & 0.75 & 0.28 \\
\hline RMSE & 30 & 9.3 & 86 & 1.1 & 0.7 & 1.9 \\
\hline$\%$ RMSE & $18 \%$ & & $42 \%$ & $15 \%$ & $75 \%$ & $28 \%$ \\
\hline$M A E$ & 23 & 6.5 & 63 & 1.0 & 0.5 & 1.6 \\
\hline$\% M A E$ & $14 \%$ & & $31 \%$ & $14 \%$ & $56 \%$ & $24 \%$ \\
\hline$M B E$ & -1.6 & -2.0 & -2.9 & -0.1 & 0.3 & -1.4 \\
\hline$\% M B E$ & $-0.9 \%$ & & $-1.4 \%$ & $-1.5 \%$ & $30 \%$ & $-20 \%$ \\
\hline
\end{tabular}

${ }^{\text {a }}$ From 0700 to 2200 CST

were oriented north-south, this corresponded to a brief period when the sun illuminated most of the soil between the crop rows. Net shortwave irradiance to the soil increased up to $80 \%$ of global shortwave irradiance, resulting in a sharp increase in $R_{N, S}$ and therefore the magnitude of $G$ (although $R_{N, S}$ was attenuated somewhat by a brief increase in $T_{S}$ ). This effect was also shown by Ham and Kluitenberg [68] for soybean with a north-south row orientation. The sharp increase in the calculated $G$ magnitude occurred before the soil heat flux wave traveled from the surface to just below the surface where it could be detected by the soil heat flux plates and thermocouples; the wave travel time and magnitude were also likely attenuated by soil water contents, which were near field capacity as the soil was irrigated to fully meet crop ET. In addition, Agam et al. ([69], 2012) showed that a north-south row orientation resulted in greater positional variability of $G$ across the interrows compared with an east-west row orientation, particularly for partial canopy cover when positional variation in sunlit and shaded soil changes during the day. In the current study, soil heat flux plates and thermocouples (used to derive $G$ at the soil surface) were deployed at only two horizontal positions (i.e., two crop row centers and two interrow centers). However, Agam et al. ([69], 2012) reported that although three measurement positions could replicate the average $G$ for two replicates of five measurement positions for an east-west row orientation, three measurement positions were inadequate for a north-south row orientation. For this reason, Ham and Kluitenberg [68] advocated development of multidimensional models to account for the positional variation of energy exchange in row crops. Hence using only two horizontal sampling positions likely contributed to the scatter in Fig. 3.

Measured $L E$ and daily ET were up to $1047 \mathrm{~W} \mathrm{~m}^{-2}$ and $14.4 \mathrm{~mm} \mathrm{~d}^{-1}$, respectively, which are typical for fully irrigated crops at the study location during days of strong regional advection (Fig. 4). When $L E>R_{N}-G$, the additional energy was provided by $H$ where energy was transferred toward the surface instead of away (i.e., $H<0$ from Eq. 2). During the daytime (when $R_{N}>100 \mathrm{~W} \mathrm{~m}^{-2}$ ), $H<0$ occurred in approximately $57 \%$ of the 15 -min measurement intervals, contributing on average $25 \% \pm 17 \%$ (SD) to total $L E$, where average $H$ was estimated by residual in the energy balance to be $-128 \pm 98$ (SD) W m ${ }^{-2}$ ) (data not shown). Tolk et al. [60] reported that $H$ contributed on average $38 \%$ of total $L E$ for fully irrigated alfalfa at our location during advective and full canopy conditions. The $L E$ and ET measurements in the present study were larger compared with those reported in previous TSEB model studies where IRTs were used $[23,24,28,30,37]$ where $L E$ was generally below $\sim 500 \mathrm{~W} \mathrm{~m}^{-2}$ and $E T$ (if reported) was below $\sim 9 \mathrm{~mm} \mathrm{~d}^{-1}$.

Using the TSEB- $T_{R}$ version, calculated vs. measured $L E$ resulted in $I O A=0.88$ and RMSE, MAE, and MBE of 67,47 , and $5.4 \mathrm{~W} \mathrm{~m}^{-2}$, respectively (Table 1, Fig. 4(a)). The RMSE and MAE were greater compared with those reported in previous TSEB studies that used IRTs, which were 31 to $55 \mathrm{~W} \mathrm{~m}^{-2}$. However, RMSE and MAE as a percentage of the measured $L E$ average (33 and 23\%, respectively), and $M B E$ were similar. If the measured $L E$ average included only daytime $L E$ (i.e., $R_{N}>100 \mathrm{~W} \mathrm{~m}^{-2}$ ), the average measured $L E$ increased from $203 \mathrm{~W} \mathrm{~m}^{-2}$ to $363 \mathrm{~W} \mathrm{~m}^{-2}$, and \%RMSE and \%MAE were reduced to $22 \%$ and $16 \%$, respectively (data not shown), which is somewhat less compared with previous TSEB studies that usually considered only daytime $L E$. Calculated vs. measured daily $E T$ (the result of converting $L E$ to 15 -min ET and summing over $24 \mathrm{~h}$ ) resulted in $I O A=0.86$ and $R M S E, M A E$, and $M B E$ of $0.6,0.5$, and $0.2 \mathrm{~mm} \mathrm{~d}^{-1}$, respectively (Table 1, Fig. 4(b)). These correspond to $9 \%, 7 \%$, and $3 \%$ of the measured average $\left(7.2 \mathrm{~mm} \mathrm{~d}^{-1}\right)$. The TSEB$T_{R}$ version resulted in similar model performance for $E$; model performance for $T$ resulted in $I O A=0.50$ and RMSE, MAE, and $M B E$ of 
(a)

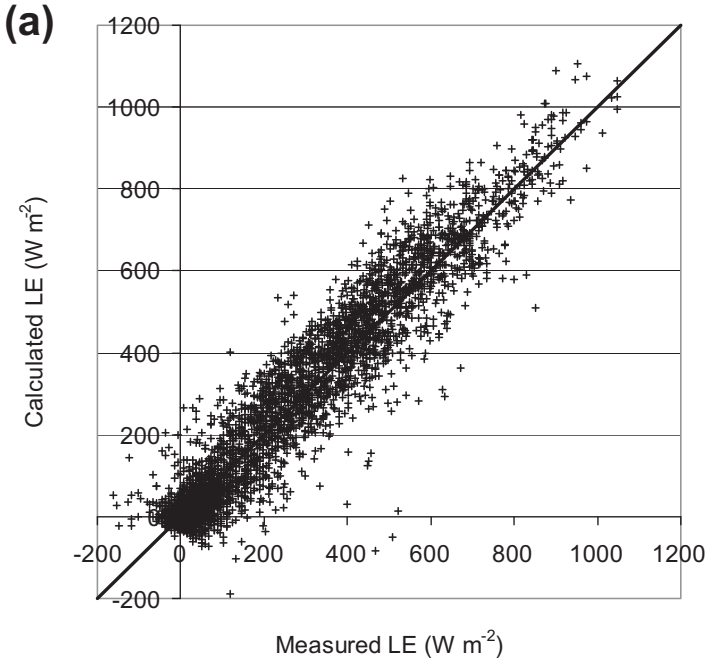

(b)

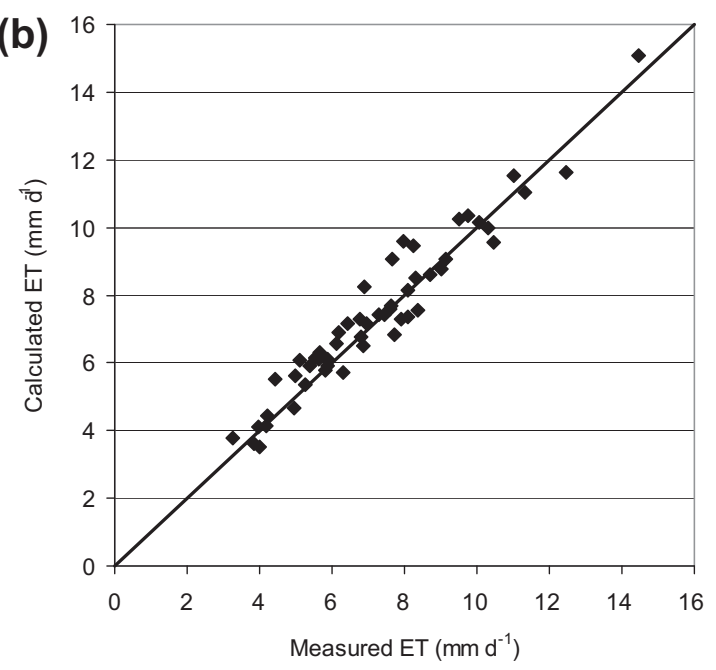

(c)

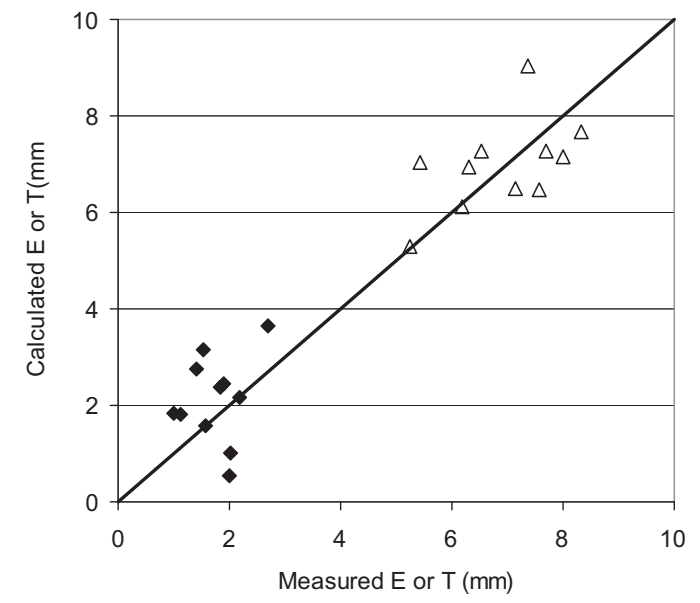

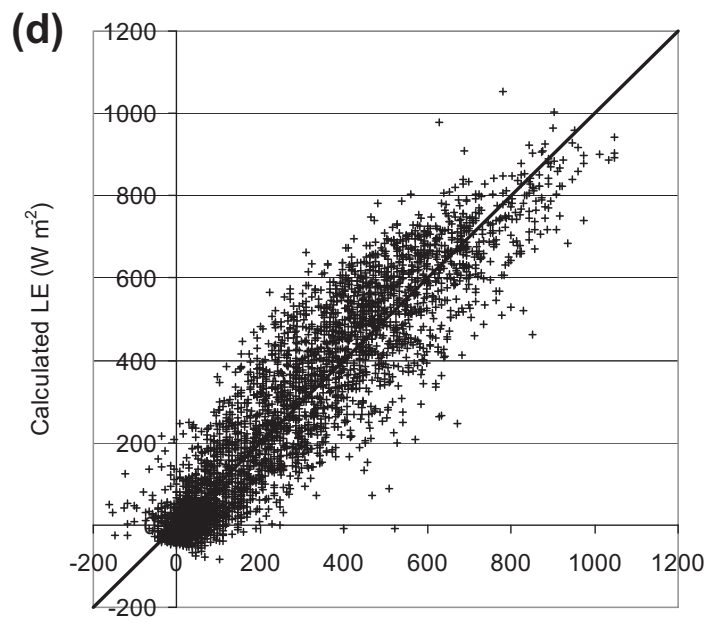

Measured LE (W m²)

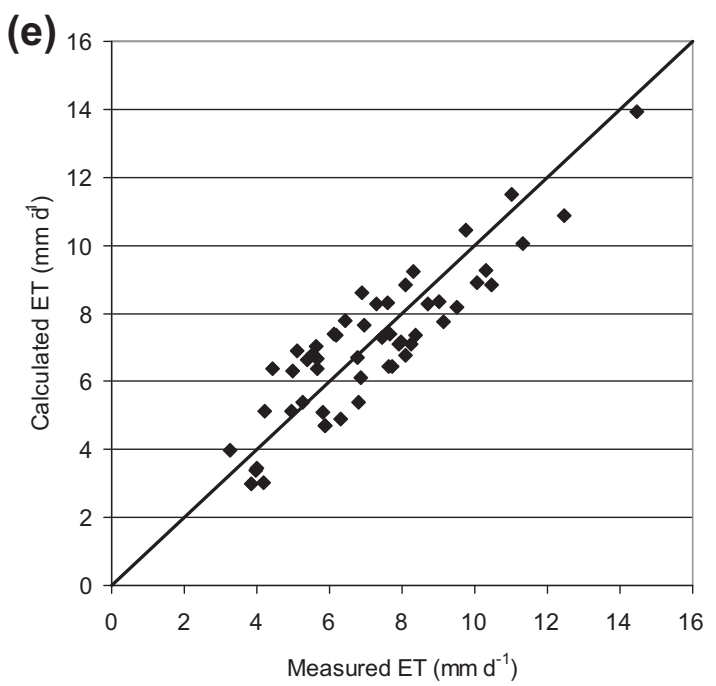

(f)
- Soil evaporation (E)
$\triangle$ Plant transpiration $(\mathrm{T})$

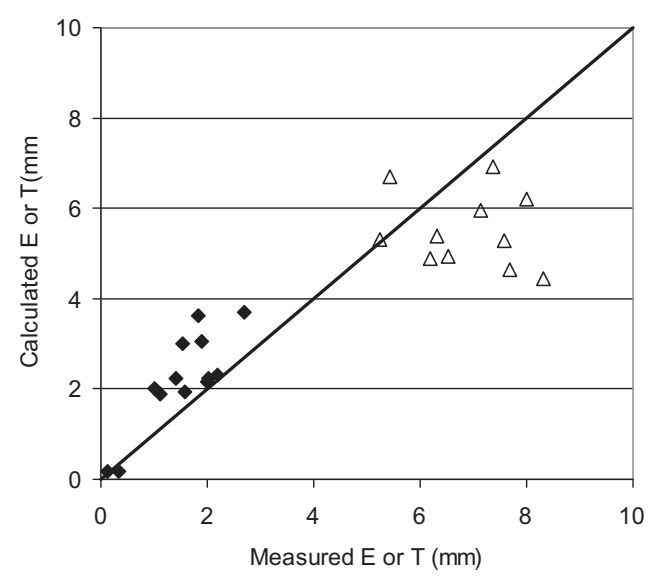

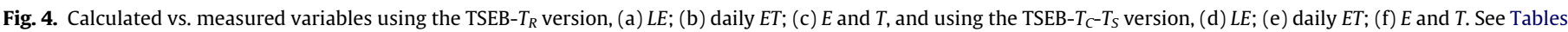
1 and 2 for statistical parameters of agreement.

$0.9,0.8$, and $0.1 \mathrm{~mm}$, respectively, but these did not include night time measurements (Table 1, Fig. 4(c)).

The TSEB- $T_{C}-T_{S}$ model version resulted in greater scatter about the 1:1 line for $L E$ and daily $E T$ (Fig. 4(d) and (e), respectively), less
IOA (0.85 and 0.71), and greater RMSE $\left(86 \mathrm{~W} \mathrm{~m}{ }^{-2}\right.$ and $\left.1.1 \mathrm{~mm} \mathrm{~d}^{-1}\right)$ and MAE ( $63 \mathrm{~W} \mathrm{~m}^{-2}$ and $1.0 \mathrm{~mm} \mathrm{~d}^{-1}$ ) compared with the TSEB- $T_{R}$ version, but slightly less magnitude of $M B E\left(-3 \mathrm{~W} \mathrm{~m}^{-2}\right.$ and $-0.1 \mathrm{~mm} \mathrm{~d}^{-1}$ ) (Table 2 ). The greater scatter between calculated 

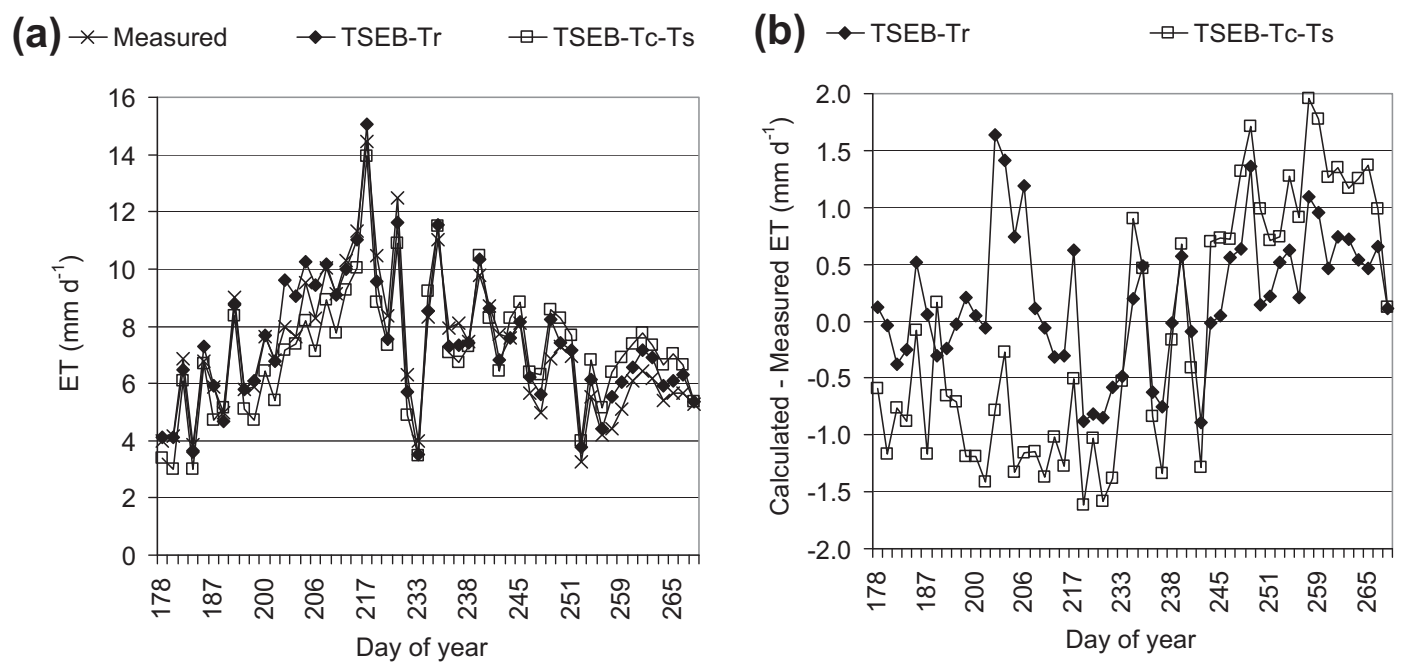

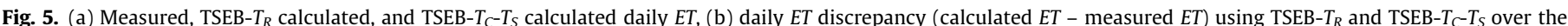
growing season.

and measured $L E$ using component temperatures (TSEB- $T_{C}-T_{S}$ version) compared with using composite temperatures (TSEB- $T_{R}$ version) was also reported by Kustas and Norman [24,36] for irrigated cotton in Arizona. In the present study, the TSEB- $T_{C}-T_{S}$ version resulted in $E$ and $T$ being overestimated $(M B E=$ $\left.0.3 \mathrm{~mm} \mathrm{~d}^{-1}\right)$ and underestimated $\left(M B E=-1.4 \mathrm{~mm} \mathrm{~d}^{-1}\right)$, respectively, to a greater extent compared with the TSEB- $T_{R}$ version (Tables 1 and 2; Fig. 4(c) and (f)).

Daily ET discrepancy (i.e., calculated - measured ET) was plotted over the growing season (Fig. 5). The largest overestimate for the TSEB- $T_{R}$ version was $1.6 \mathrm{~mm} \mathrm{~d}^{-1}$ on DOY $202\left(20 \%\right.$ of $8.0 \mathrm{~mm} \mathrm{~d}^{-1}$ measured at the lysimeter); the largest underestimate was $-0.90 \mathrm{~mm} \mathrm{~d}^{-1}$ on DOY $241\left(12 \%\right.$ of $7.7 \mathrm{~mm} \mathrm{~d}^{-1}$ measured at the lysimeter). These discrepancies may have been related to local spatial variation in soil water content ([44], 2012) and plant phenology ([13], 2012) between the lysimeter and Primary sites. In fact, Agam et al. ([13], 2012) reported that measurements of $E+T$ were up to $1.6 \mathrm{~mm}$ greater than $E T$, which is comparable to the ET discrepancies shown in Fig. 5. The discrepancies may have also been related to inconsistencies between model assumptions and directional brightness temperature measurements, which will be discussed further.

The TSEB- $T_{C}-T_{S}$ version yielded smaller daily ET compared with lysimeter measurements early in the season, from DOY 178 to 223 (except for DOY 188), both under- and overestimated measured daily ET from DOY 233 to 241, and consistently calculated larger daily ET from DOY 244 to 267 (Fig. 5). The TSEB- $T_{R}$ version also consistently calculated larger daily $E T$ later in the season, but the magnitudes were not as large as those for the TSEB- $T_{C}-T_{S}$ version. The bias compared with measurements using the TSEB- $T_{C}-T_{S}$ version at different times of the season is also visible by the two clusters of points both above and below the 1:1 line in Fig. 4(e). From Fig. 2, the period up to DOY 223 corresponded to increasing $f_{V R}$ and $L A I$, DOY 233 to 241 occurred during maximum $f_{V R}$ and $L A I$, and after DOY 244, $f_{V R}$ and $L A I$ began to decrease as leaves began to senesce. The largest overestimate of daily $E T$ was $2.0 \mathrm{~mm} \mathrm{~d}^{-1}$ on DOY 258 ( $44 \%$ of $4.4 \mathrm{~mm} \mathrm{~d}^{-1}$ measured at the lysimeter); the largest underestimate was $-1.6 \mathrm{~mm} \mathrm{~d}^{-1}$ on DOY 218 (15\% of $10.4 \mathrm{~mm} \mathrm{~d}^{-1}$ measured at the lysimeter) (Fig. 5).

\subsection{Model assumptions and temperature measurements}

The smaller daily ET by the TSEB- $T_{C}-T_{S}$ version early in the season (up to DOY 223) may have been related to inconsistencies between model assumptions and $T_{C}$ and $T_{S}$ measurements. A key assumption of both TSEB model versions is that the effective source/sink for turbulent flux exchange for the entire canopy can be described by a single bulk temperature and resistance (i.e., $T_{C}$ and $r_{X}$, respectively), as well as the entire substrate (soil) surface (i.e., $T_{S}$ and $r_{S}$, respectively). For $T_{C}$ and $r_{X}$, this avoids the additional complexity of multiple canopy layers [23]. Thus the effective $T_{C}$ and $r_{X}$ consider the contribution of the entire canopy, which includes sunlit and shaded leaves, transpiring and non-transpiring elements, and microscale temperature differences caused by gradients and eddies (e.g. [912]). For $T_{S}$ and $r_{S}$, large differences may exist for sunlit and shaded soil, and the relative proportions depend on direct beam irradiance, which varies with time of day due to solar zenith angle and azimuth angle relative to crop rows [36,69]. Ham and Kluitenberg [68] showed that substantial variation in the overall energy balance results along the soil surface perpendicular to north-south oriented crop rows, and concluded that the energy balance cannot be realistically modeled using a single $T_{S}$.

During the early part of the season when the canopy was relatively small (i.e., $0.2 \mathrm{~m}<w_{C}<0.8 \mathrm{~m}, 0.2 \mathrm{~m}<h_{C}<0.9 \mathrm{~m}$, and 0.1 $\mathrm{m}^{2} \mathrm{~m}^{-2}<L A I<3 \mathrm{~m}^{2} \mathrm{~m}^{-2}$ ), there may have been some limitations in obtaining the effective $T_{C}$ using IRTs with a near-horizontal view. If the canopy did not completely fill the IRT field of view, then $T_{C}$ measurements may have included downwelling hemispherical longwave irradiance from the sky, as well as upwelling longwave

Table 3

Comparison of measured $T_{R}$ and measured $T_{C}$, early season (DOY 193 to 223), mid season (DOY 233 to 241, and late season (DOY 244 to 258). See Fig. 6 for scatter plots.

\begin{tabular}{lccc}
\hline & Early season, & Mid season, & Late season, \\
& $T_{R}$ vs. $T_{\mathrm{C}}\left({ }^{\circ} \mathrm{C}\right)$ & $T_{R}$ vs. $T_{\mathrm{C}}\left({ }^{\circ} \mathrm{C}\right)$ & $T_{R}$ vs. $T_{\mathrm{C}}\left({ }^{\circ} \mathrm{C}\right)$ \\
\hline$n=$ & 998 & 443 & 523 \\
Measured & 25.5 & 22.6 & 19.4 \\
$\quad$ average $T_{C}$ & & & \\
Measured $S D T_{C}$ & 3.6 & 3.1 & 3.6 \\
Measured & 24.8 & 22.6 & 19.9 \\
$\quad$ average $T_{R}$ & & & \\
Measured $S D T_{R}$ & 3.8 & 3.1 & 3.9 \\
$I O A$ & 0.98 & 0.99 & 0.98 \\
$R M S E$ & 1.8 & 0.61 & 1.0 \\
$\% R M S E$ & $7.0 \%$ & $2.7 \%$ & $5.1 \%$ \\
$M A E$ & 1.1 & 0.46 & 0.74 \\
$\% M A E$ & $4.1 \%$ & $2.0 \%$ & $3.8 \%$ \\
$M B E$ & -0.93 & 0.01 & 0.49 \\
$\% M B E$ & $-3.7 \%$ & $0.1 \%$ & $2.5 \%$ \\
\hline
\end{tabular}


irradiance from the soil, resulting in a positive bias. Inspection if Eq. (1) and (3) indicate that if $T_{C}$ measurements had positive bias, $L E_{C}$ (and hence $T$ and $E T$ ) would be underestimated, all other variables being the same. Comparison of $T_{R}$ and $T_{C}$ measurements from DOY 193 to DOY 223 showed that $T_{R}$ tended to be less than $T_{C}$, where $M B E=-0.93^{\circ} \mathrm{C}$ (Table 3, Fig. 6(a)). This is despite $T_{R}$ having a nadir view, which included soil background, and daytime $T_{S}$ exceeded $T_{C}$ by up to $24^{\circ} \mathrm{C}$ at midday (data not shown), whereas the IRTs used to measure $T_{C}$ had near-horizontal views along the canopy row. No attempt was made to account for the possibility of greater downwelling (or upwelling) longwave irradiance reaching the horizontal-viewing IRTs during partial canopy cover, as this remains speculation despite the indirect evidence from comparing $T_{R}$ and $T_{C}$ measurements. In addition, $T_{C}$ measurements may have included a greater proportion of sunlit leaves in the top area of the canopy, compared with $T_{R}$, which likely included shaded leaves
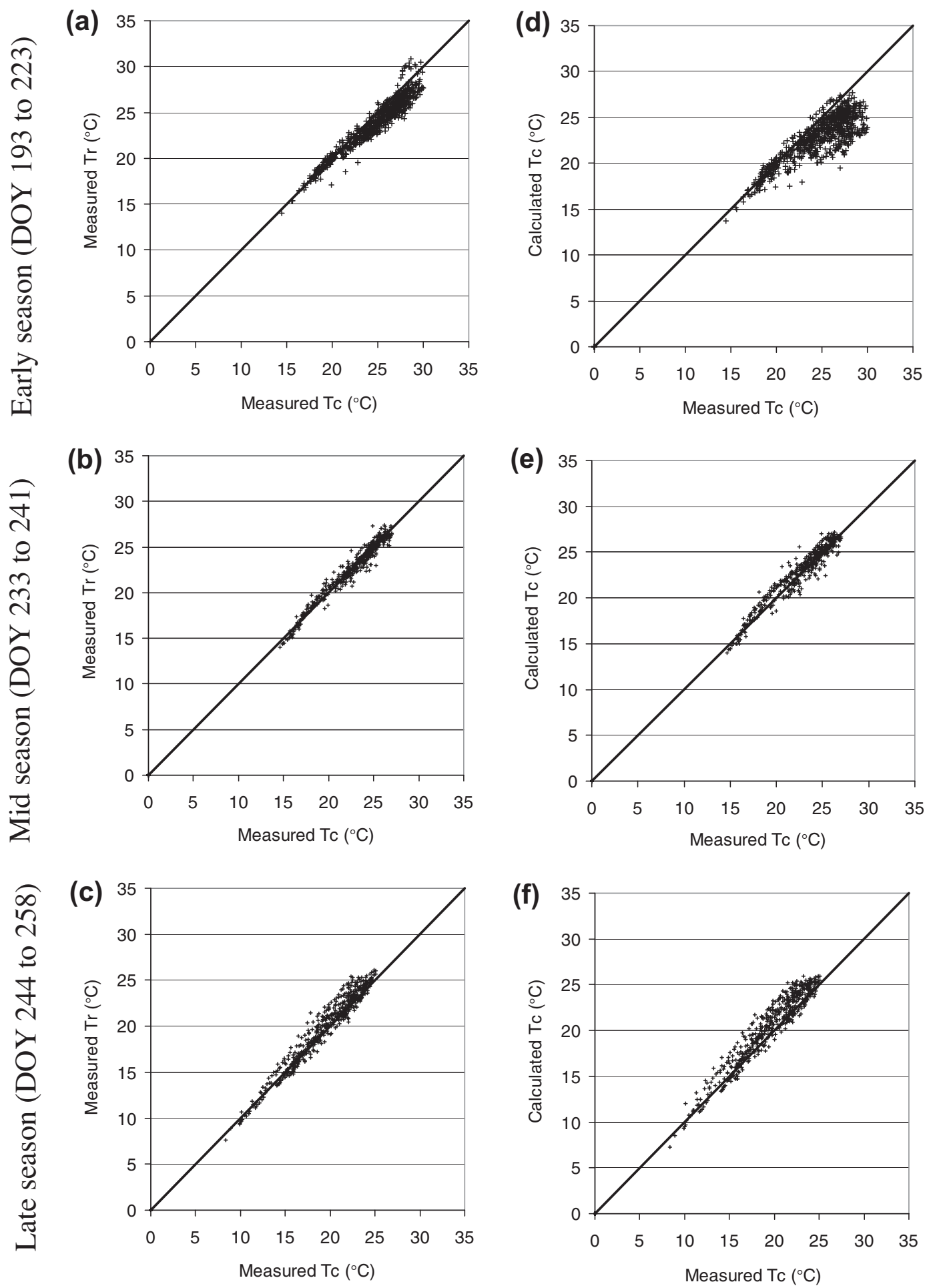

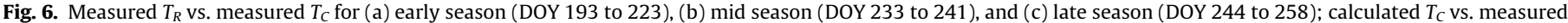

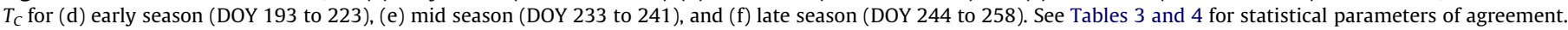


deep in the canopy (although this may have been offset by an inverted temperature gradient within the canopy caused by warmer soil; $[9,11,70])$. Wanjura and Upchurch [71] compared $T_{C}$ measurements using an IRT for the south and north sides of an east-west oriented cotton row, and reported that the south side of the row (which would contain a greater proportion of sunlit leaves) was $0.7^{\circ} \mathrm{C}$ greater $(p<0.01)$ compared with the north side of the row. The calculated $T_{C}$ resulting from the TSEB- $T_{R}$ model version also tended to be less than measured $T_{C}$, where $M B E=-2.2^{\circ} \mathrm{C}$ (Table 4, Fig. $6(d)$ ), implying that calculated $T_{C}$ would be less than measured $T_{R}$, as expected for partial canopy cover.

Underestimates of $T$ by the TSEB- $T_{C}-T_{S}$ version (Fig. 4(f)) may have resulted from the same processes (i.e., non-canopy longwave irradiance reaching the IRT and a larger proportion of sunlit leaves appearing in the IRT field of view) as just described for the daily $E T$ underestimates, since $T$ measurements were obtained only during the early part of the season (DOY 203 to 213; Fig. 2(e)). In addition, Agam et al. ([13], 2012) showed that $T$ and $E+T$ measurements at the Primary site were sometimes larger than ET measured at the nearby lysimeter, suggesting that $T$ derived from sap flow gauges was overestimated. This was thought to be related to difficulties in estimating plant area when converting sap flow measurements to $T$, and was probably confounded by the local spatial variability of plant phenology. Hence both calculation underestimates and measurement overestimates could have contributed to $T$ discrepancies in a consistent manner.

Overestimates of $E$ by the TSEB- $T_{C}-T_{S}$ version (Fig. 4(f)) may have partially offset early season ET underestimates (Fig. 5(b)). We postulate that $E$ overestimates were more likely related to model assumptions and $T_{S}$ measurements being limited to a small portion $(\sim 0.06 \mathrm{~m})$ of the center interrow rather than $E$ measurements. Similar to $T$, measurements of $E$ were obtained early in the season, although over a larger range of canopy cover and LAI (Fig. 2(d)). Although the E/ET ratio varied from $\sim 50$ to $30 \%$ as the canopy developed, the magnitude of $E$ remained relatively constant ( $\sim 2 \mathrm{~mm}$ ) regardless of canopy size (Fig. 4(e) and 4(f)). The microlysimeters used to measure $E$ likely had greater accuracy and precision (i.e., $0.01 \mathrm{~mm}$ water equivalent) compared with $T$ measurements ([13], 2012). The microlysimeters were based on direct measurement of mass, and therefore were not subject to estimates of plant area and other potential errors related to converting sap flow to T. Furthermore, Agam et al. ([13], 2012) showed that total daily $E$ was nearly the same regardless of microlysimeter position within the crop interrows, because direct beam solar irradiance was the primary driver of $E$, and portions of the interrows were illuminated from west to east in a uniform manner as the sun passed over crop rows with a north-south orientation. Thus

\section{Table 4}

Statistical parameters of agreement for calculated vs. measured $T_{C}$ using the TSEB- $T_{R}$ model version, early season (DOY 193 to 223), mid season (DOY 233 to 241, and late season (DOY 244 to 258). See Fig. 6 for scatter plots.

\begin{tabular}{lccc}
\hline & $\begin{array}{c}\text { Early season, } \\
T_{C}\left({ }^{\circ} \mathrm{C}\right)\end{array}$ & $\begin{array}{l}\text { Mid season, } \\
T_{C}\left({ }^{\circ} \mathrm{C}\right)\end{array}$ & $\begin{array}{l}\text { Late season } \\
T_{C}\left({ }^{\circ} \mathrm{C}\right)\end{array}$ \\
\hline$n=$ & 998 & 443 & 523 \\
Measured average & 25.5 & 22.6 & 19.4 \\
Measured $S D$ & 3.6 & 3.1 & 3.6 \\
Calculated average & 23.2 & 22.8 & 20.4 \\
Calculated $S D$ & 2.6 & 3.1 & 3.9 \\
IOA & 0.95 & 0.99 & 0.97 \\
RMSE & 3.1 & 0.83 & 1.4 \\
$\%$ RMSE & $12 \%$ & $3.7 \%$ & $7.2 \%$ \\
MAE & 2.3 & 0.65 & 1.1 \\
$\%$ MAE & $8.9 \%$ & $2.9 \%$ & $5.8 \%$ \\
$M B E$ & -2.2 & 0.22 & 0.91 \\
$\%$ MBE & $-8.6 \%$ & $1.0 \%$ & $4.7 \%$ \\
\hline
\end{tabular}

the positional variation of available energy and turbulent flux [68] appeared to be compensating over the day, which may have been a mitigating factor for the relatively small portion of the center interrow included in $T_{S}$ measurements.

Daytime $T_{S}$ measurements were as expected for a north - south crop row orientation with partial cover. A distinct peak occurred a few hours around solar noon when the interrow center was illuminated by direct beam irradiance (Fig. 7(a)), similar to Ham and Kluitenberg [68] for soybean with partial cover. During this time period, measured $T_{S}$ was almost $15^{\circ} \mathrm{C}$ larger than calculated $T_{S}$ used in the TSEB- $T_{R}$ version, but was less than calculated $T_{S}$ during other times. Calculated vs. measured $T_{S}$ had greater scatter early in the season (DOY 193 to 223; Table 5, Fig. 7(d)) compared with calculated vs. measured $T_{C}$ during the same period (Table 4, Fig. 6(d)). This was likely related to measured $T_{S}$ being over mostly shaded soil much of the day (expect a few hours around solar noon when the interrow center was sunlit), whereas calculated $T_{S}$ represents the bulk surface containing both sunlit and shaded soil throughout the day. Most $T_{S}$ measurements included $<50 \%$ sunlit soil in the IRT view (the proportion of sunlit soil in the IRT view was calculated following Colaizzi et al. [45]), and these tended to be less than calculated $T_{S}$ (Fig. 7(d)). A smaller proportion of $T_{S}$ measurements had $>50 \%$ sunlit soil, and most of these were larger than calculated $T_{S}$, as expected (Fig. $7(\mathrm{~d})$ ). Overall, calculated $T_{S}$ was larger than measured $T_{S}\left(M B E=0.75^{\circ} \mathrm{C}\right.$, Table 5), again likely the result of measured $T_{S}$ representing mostly shaded soil. If $T_{S}$ measurements at several locations across the interrow were used, spatially averaged values may have been larger than $T_{S}$ measurements reported here because the former would also include a larger portion of sunlit soil. From Eq. (3), it then follows that spatially averaged $T_{S}$ may have mitigated overestimates of $E$ by the TSEB- $T_{C}-T_{S}$ version. An even more physically realistic approach would have been to model the energy balance of the sunlit and shaded portions of the interrows separately [68].

During the mid season (DOY 223 to 241) when $L A I$ reached the seasonal maximum (LAI $\sim 3 \mathrm{~m}^{2} \mathrm{~m}^{-2}$ ), both the TSEB- $T_{C}-T_{S}$ and TSEB- $T_{R}$ versions resulted in similar ET discrepancies (Fig. 5). As expected for full canopy cover, there were very little differences between measured $T_{R}$ and measured $T_{C}$ (Table 3, Fig. 6(b), $M B E=0.01{ }^{\circ} \mathrm{C}$ ), and calculated vs. measured $T_{C}$ (Table 4, Fig. 6(e), $M B E=0.22^{\circ} \mathrm{C}$ ). In this case, $T_{R}$ apparently viewed the same portion of the canopy as $T_{C}$ (i.e., near the top), so that vertical temperature gradients in the canopy, if present, did not influence measurements. Also, the $T_{R}$ and $T_{C}$ IRTs apparently viewed the same proportion of sunlit and shaded leaves, despite the differences in view angles (i.e., nadir and near-horizontal, respectively). The close agreement between calculated and measured $T_{C}$ lent support for the secant method used to solve the series resistance network, and use of the Penman-Monteith formulation therein, as described in Appendix B. Measured $T_{S}$ was usually less than measured and calculated $T_{C}$ during most of the daytime, except around solar noon when $T_{S}$ increased sharply (Fig. 7(b)). This was similar to the early season pattern during partial cover (Fig. 7(a)), but mid season measured and calculated $T_{S}$ had smaller daytime variability, as would be expected for mostly shaded soil (Table 5, Fig. 7(e)) Although most direct beam irradiance would be intercepted by the canopy during the mid season, a small portion nonetheless reached the interrow center around solar noon.

During the late season (after DOY 244), both the TSEB- $T_{C}-T_{S}$ and TSEB- $T_{R}$ versions calculated larger daily ET compared with lysimeter measurements; overestimates were almost $2 \mathrm{~mm} \mathrm{~d}^{-1}$ greater for the former compared with the latter model version on some days (Fig. 5). This again may have resulted from inconsistencies between the $T_{C}$ that represents the effective source/sink of turbulent exchange in the canopy (i.e., the $T_{C}$ that results in $H$ and $L E$ for the entire canopy) and the portions of the canopy appearing in the IRT 
(a)

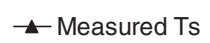

$\rightarrow-$ Measured Tc

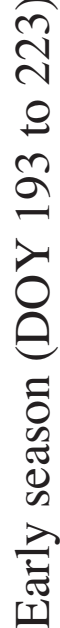

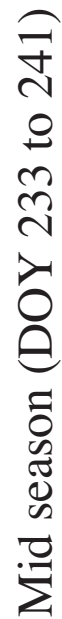

(b) $\quad \pm$ Measured Ts $\triangle$ Calculated Ts

$\rightarrow$ Calculated Tc

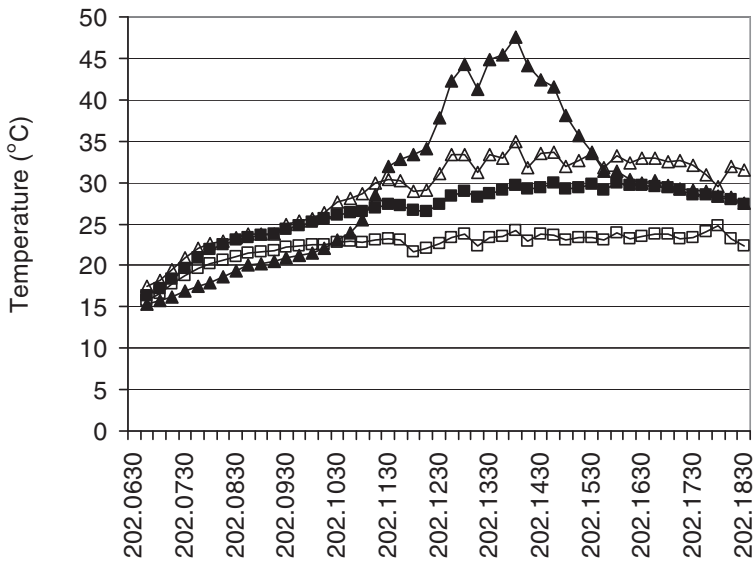

DOY.Time

$\triangle$ Calculated Ts

$\because$ Calculated Tc

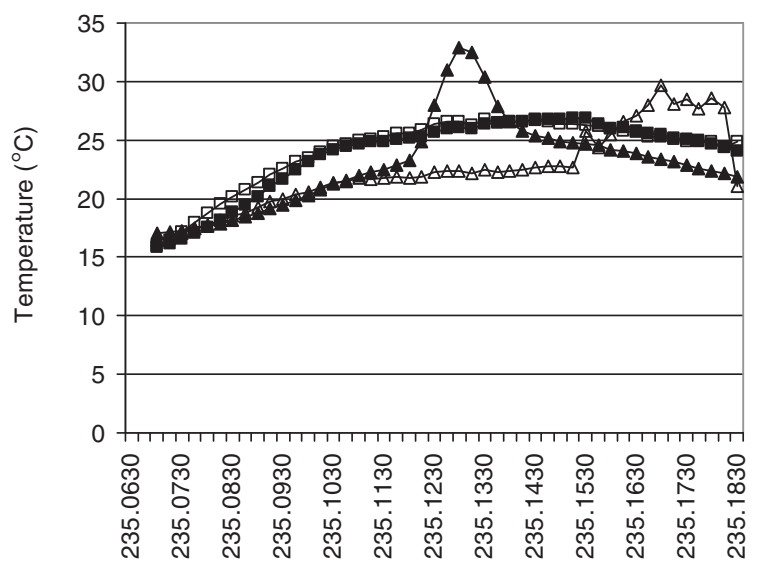

DOY.Time

(c) $\quad$ - Measured Ts

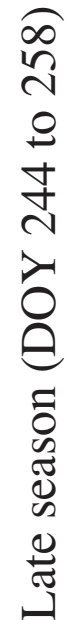

$\triangle$ Calculated Ts

$\square-$ Calculated Tc

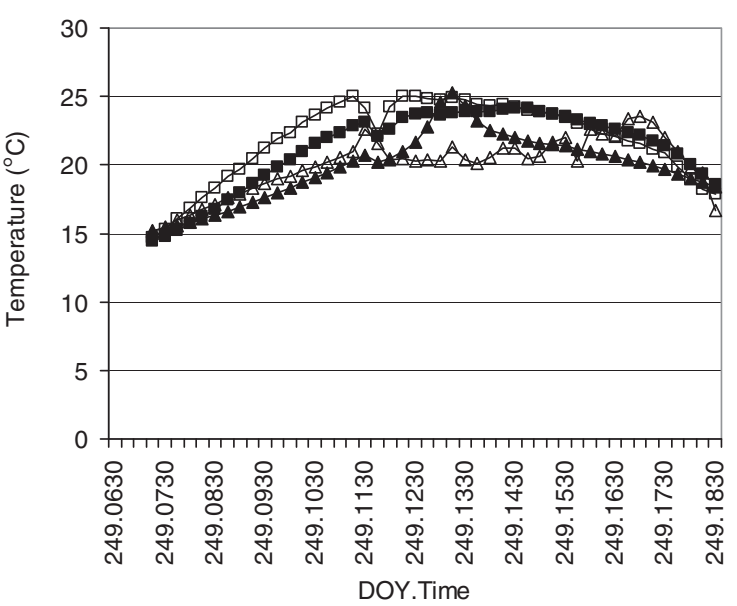

(d)

+ Sunlit soil $<50 \% \quad \circ$ Sunlit soil $=>50 \%-1: 1$ Line

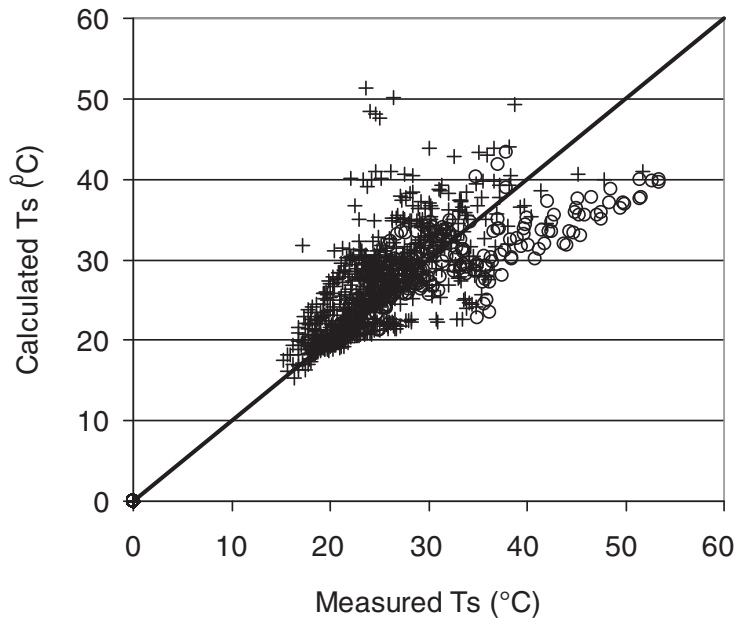

(e)

+ Sunlit soil $<50 \%$ ○ Sunlit soil $=>50 \%-1: 1$ Line

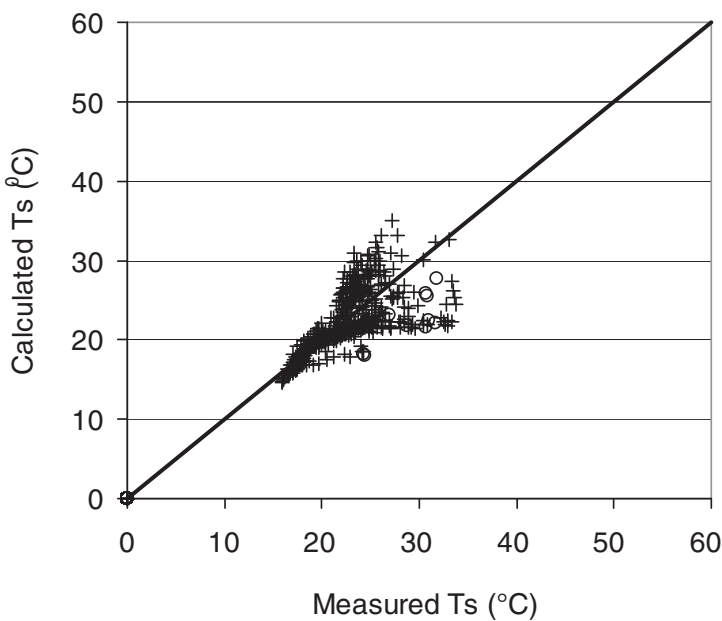

(f) + Sunlit soil $<50 \% \circ$ Sunlit soil $=>50 \%-1: 1$ Line

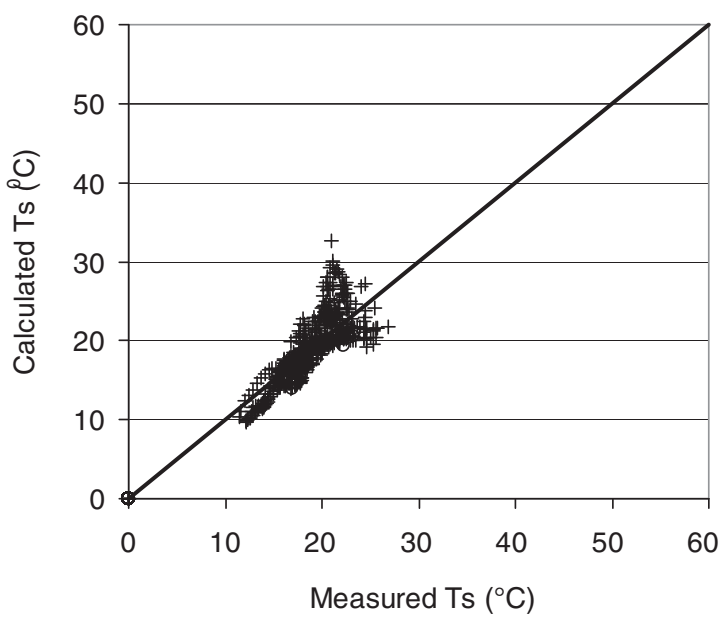

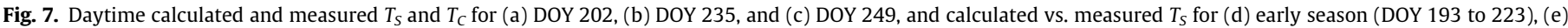
mid season (DOY 233 to 241), and (f) late season (DOY 244 to 258); see Table 5 for statistical parameters of agreement. 
Table 5

Statistical parameters of agreement for calculated vs. measured $T_{S}$ using the TSEB- $T_{R}$ model version, early season (DOY 193 to 223), mid season (DOY 233 to 241, and late season (DOY 244 to 258). See Fig. 7 for scatter plots.

\begin{tabular}{lccc}
\hline & Early season, & Mid season, & Late season, \\
& $T_{S}\left({ }^{\circ} \mathrm{C}\right)$ & $T_{S}\left({ }^{\circ} \mathrm{C}\right)$ & 523 \\
& 998 & 443 & 18.9 \\
\hline$n=$ & 27.2 & 22.8 & 2.9 \\
Measured average & 7.5 & 3.7 & 19.0 \\
Measured $S D$ & 27.8 & 22.4 & 4.0 \\
Calculated average & 6.4 & 3.8 & 0.95 \\
Calculated $S D$ & 0.93 & 0.95 & 2.4 \\
$I O A$ & 5.0 & 3.2 & $13 \%$ \\
RMSE & $18 \%$ & $14 \%$ & 1.8 \\
$\%$ RMSE & 3.3 & 2.3 & $9.4 \%$ \\
MAE & $12 \%$ & $10 \%$ & 0.08 \\
$\%$ MAE & 0.75 & -0.40 & $0.44 \%$ \\
$M B E$ & $2.8 \%$ & $-1.7 \%$ & \\
$\%$ MBE & & &
\end{tabular}

field of view (either measured or calculated $T_{C}$ ). Later in the season, leaves began to senesce and $L A I$ decreased, and the proportion of non-transpiring elements in the canopy increased. By the late season, $h_{C}$ was 1.0 to $1.1 \mathrm{~m}$ (Fig. 2(b)), and the IRTs used to measure $T_{C}$ were deployed $\sim 0.7-\mathrm{m}$ above the soil surface. The progression of flowering, boll formation, and leaf senescence was observed to move from the lower (older) area of the canopy towards the top (newer) portion of the canopy. This would imply that a greater proportion of transpiring elements appeared in the near-horizontal IRT field of view compared with that actually present in the canopy. This would usually result in measured $T_{C}$ being less than the $T_{C}$ of the effective source/sink of turbulent exchange, and therefore resulting in overestimates of $L E$ and $E T$ by the TSEB- $T_{C}-T_{S}$ version (cf. Eq. 1 and 3). Similarly, $T_{R}$ measurements (by the nadir-viewing IRT) may have also included a greater proportion of transpiring elements compared with that actually present in the canopy, but perhaps not to the extent as measured $T_{C}$, because a greater proportion of non-transpiring elements would be visible deeper in the canopy from the nadir view. Also, cotton leaves become less diaheliotropic later in the season, which may due to leaf age and also reductions in soil water content, resulting in leaves being oriented more vertically throughout the day [72], exposing a deeper portion of the canopy to a nadir view. Measured $T_{R}$ tended to be greater compared with measured $T_{C}$ (Table 3, Fig. $6(\mathrm{c}), M B E=0.49^{\circ} \mathrm{C}$ ), as did calculated $T_{C}$ (Table 4 , Fig. $6(\mathrm{f}), M B E=0.91^{\circ} \mathrm{C}$ ), but the TSEB- $T_{R}$ model version nonetheless calculated greater $E T$ later in the season compared with lysimeter measurements. Late season ET overestimates were also reported by French et al. [31] for wheat, and they attributed this to leaf senescence. In order to account for reductions in transpiring elements, the Priestley-Taylor approximation (see Eq. 6) used in the original TSEB- $T_{R}$ formulation of Norman et al. [23] includes $f_{G}$ (the proportion of green vegetation). Although not attempted in the present study, this could also be accomplished in the Penman-Monteith approach (Eq. 7) by simply increasing $r_{C}$ later in the season. Late season measured and calculated $T_{S}$ patterns were similar to those during mid season, but calculated vs. measured $T_{S}$ scatter was smaller (Table 5, Fig. 7). Similar to the mid season, $T_{S}$ was usually less than $T_{C}$ because the interrow was shaded except in the center around solar noon (Fig. 7(c)).

\section{Summary and Conclusions}

The TSEB- $T_{R}$ model version resulted in $\sim 6$ to $9 \%$ less $R M S E$ and $M A E$ for calculated vs. measured $L E$ and daily $E T$ compared with the TSEB- $T_{C}-T_{S}$ model version; $M B E$ for both versions was within $3 \%$ of measured means of $L E$ and daily ET. The greater RMSE and $M A E$ observed for the TSEB- $T_{C}-T_{S}$ version was related to consistent discrepancy trends during different parts of the cotton growing season. The TSEB- $T_{C}-T_{S}$ version consistently underestimated measured daily ET early in the season (before the canopy developed to full cover), and both model versions consistently overestimated measured daily ET later in the season (when the canopy contained non-transpiring elements such as flowers, bolls, and senesced leaves). Late season overestimates were up to $2 \mathrm{~mm}$ larger for the TSEB- $T_{C}-T_{S}$ version compared with the TSEB- $T_{R}$ version. During mid season when canopy cover was full and $L A I$ was at the seasonal maximum ( $L A I \sim 3 \mathrm{~m}^{2} \mathrm{~m}^{-2}$ ), both model versions resulted in similar calculated daily $E T$, with similar discrepancies of $\pm 1.3 \mathrm{~mm} \mathrm{~d}^{-1}$. Measurements of $T_{C}$ and $T_{R}$ were nearly the same during mid season, with $R M S E=0.6^{\circ} \mathrm{C}$ and $M B E=0.01^{\circ} \mathrm{C}$.

The TSEB- $T_{R}$ version also partitioned $E$ and $T$ with less $M B E$ compared with the TSEB- $T_{C}-T_{S}$ version, with TSEB- $T_{C}-T_{S}$ calculating $T$ that tended to be less than measurements $(M B E=-20 \%)$ and calculating $E$ that tended to be greater than measurements $(M B E=30 \%)$, whereas TSEB- $T_{R}$ had MBE $<2 \%$ compared with $E$ and $T$ measurements. However, $E$ and $T$ measurements were available only during the early part of the season; therefore, additional studies are needed to determine how well both TSEB versions can partition $E$ and $T$ during other parts of the season. Also, $T$ measurements may have been overestimated ([13], 2012), and so differences between calculated and field-averaged $T$ using the TSEB- $T_{C}-T_{S}$ version may not have been as large as reported here. Nonetheless, the early season underestimates of measured daily $E T$ by the TSEB- $T_{C}-T_{S}$ version were likely related to underestimates of $T$, since $T \geqslant \sim 50 \%$ of ET after DOY 175 ([13], 2012).

The differences in calculated vs. measured daily ET during the early and later parts of the cotton season may have been related to inconsistencies between the model assumption of a single $T_{C}$ and $T_{S}$ representing the source/sink of turbulent fluxes for the bulk canopy and substrate surfaces, respectively, and actual $T_{C}$ and $T_{S}$ measurements. Early in the season before full canopy cover was reached, $T_{C}$ measurements may have been biased upward by downwelling longwave irradiance from the atmosphere, and also a greater proportion of sunlit leaves appearing in the IRT view compared with the ensemble canopy. Although IRTs used to measure $T_{R}$ had a nadir view (i.e., pointed at the soil and canopy directly) and IRTs used to measure $T_{C}$ had a near-horizontal view, $T_{R}$ tended to be less than $T_{C}$ with $M B E=-0.93^{\circ} \mathrm{C}$. The upward $T_{C}$ bias would have resulted in $T$ and $E T$ underestimates according to Eq. (1) and (3). Later in the season, the canopy contained a greater proportion of non-transpiring elements such as flowers, bolls, and senesced leaves, and a larger proportion of these elements were located toward the lower (older) part of the canopy, whereas $T_{C}$ and $T_{R}$ measurements contained a greater proportion of the upper (newer) part of the canopy that contained a greater proportion of transpiring elements. This may have resulted in a downward bias of $T_{C}$ and $T_{R}$, resulting in $E T$ overestimates.

Measurements of $E$ were available only during the early part of the season during partial canopy cover, and $E$ as calculated by the TSEB- $T_{C}-T_{S}$ model version was consistently greater than $E$ measurements. This may have been related to $T_{S}$ being measured in the interrow center over a relatively small area $(\sim 0.06 \mathrm{~m})$, which did not represent the positional variation due to direct beam irradiance that is especially inherent in partial canopy cover [68]. Since the area of $T_{S}$ measurements was shaded during most of the day (except around solar noon), the bulk $T_{S}$ may have been underestimated throughout the day, as measured $T_{S}$ tended to be larger compared with the calculated $T_{S}$ used in the TSEB- $T_{R}$ model version $(M B E=0.75 C)$, leading to $E$ overestimates (Eq. (1) and (3)). This result suggests that the TSEB might be improved by accounting for the energy balance of the sunlit and shaded substrate separately.

The overall performance of the TSEB in the semiarid, advective climate, where the model was tested against lysimeter measurements 
of $E T$, was comparable to previous TSEB studies, where $L E$ and $E T$ were indirectly derived from other methods (e.g., Bowen ratio, eddy covariance, METFLUX). Throughout the cotton season, the use of composite radiometric surface temperature was superior compared with using component (soil and canopy) radiometric temperatures to calculate $L E$ and daily $E T$ using the TSEB. Although composite radiometric surface temperature was also superior to calculate $E$ and $T$ compared with component temperatures, this was evaluated only during the first part of the growing season. It appears the secant method used to solve the series resistance network of equations in the TSEB- $T_{R}$ model version, where initial $T_{C}$ was estimated using a form of the Penman-Monteith equation, was suitable for a fully irrigated cotton crop. This approach assumes non-water-stressed conditions, but does contain a provision to increase $r_{C}$ incrementally to achieve a realistic energy balance solution (analogous to decreasing the Priestley-Taylor $\alpha_{P T}$ parameter used in the original TSEB formulation). Future studies should address limited irrigation or dryland production systems where water stress would be expected to be more prevalent (resulting in greater $T_{C}$ compared with fully irrigated conditions), other crops, and $E$ and $T$ partitioning throughout the crop season.

\section{Acknowledgements}

This research was supported by the USDA-ARS National Program 211, Water Availability and Watershed Management and in part by the Ogallala Aquifer Program, a consortium between USDA-Agricultural Research Service, Kansas State University, Texas AgriLife Research, Texas AgriLife Extension Service, Texas Tech University, and West Texas A\&M University. We are grateful to Dr. Andrew French, USDA-ARS, Maricopa, Arizona for allowing us to use the Cimel multiband thermal radiometer and for his critical reviews of this and previous manuscripts. We thank the numerous biological technicians and student workers for their meticulous and dedicated efforts in executing experiments and obtaining and processing data.

\section{Appendix A}

Net radiation to the canopy $\left(R_{N, C}\right)$ and soil $\left(R_{N, S}\right)$ were calculated as the sum of their net shortwave and longwave components:

$R_{N, C}=S_{N, C}+L_{N, C}$

$R_{N, S}=S_{N, S}+L_{N, S}$

where $S_{N, C}$ is the net shortwave radiation to the canopy, $L_{N, C}$ is the net longwave radiation to the canopy, $S_{N, S}$ is the net shortwave radiation to the soil, and $L_{N, S}$ is the net longwave radiation to the soil, all in units of $\mathrm{W} \mathrm{m}^{-2}$. The shortwave radiation components include visible ( $\sim 400$ to $\sim 700 \mathrm{~nm}$ spectra) and near infrared $(\sim 700$ to $\sim 2800 \mathrm{~nm}$ spectra), which can be further partitioned into their direct beam and diffuse components. Each of these four shortwave subcomponents differ in their transmittance and reflectance properties. Therefore, transmittance and reflectance were calculated separately for each subcomponent by the Campbell and Norman [48] radiative transfer model, which was combined with geometric-based view factors (that account for the non-random spatial distribution of row crop vegetation) developed by Colaizzi et al. [46]. In this approach, $S_{N, C}$ is calculated as

$S_{N, C}=S_{N, C, V I S, D I R}+S_{N, C, V I S, D I F F}+S_{N, C, N I R, D I R}+S_{N, C, N I R, D I F F}$

where the subscripts VIS, NIR, DIR, and DIFF refer to the visible, near infrared, direct beam, and diffuse shortwave subcomponents, respectively, all in $\mathrm{W} \mathrm{m}^{-2}$, and

$$
\begin{aligned}
& S_{N, C, V I S, D I R}=R_{S} f_{V I S}\left[K_{b, V I S} f_{S C}\left(1-\tau_{C, D I R, V I S}\right)\left(1-\rho_{C, D I R, V I S}\right)\right] \\
& S_{N, C, V I S, D I F F}=R_{S} f_{V I S}\left[\left(1-K_{b, V I S}\right) f_{D H C}\left(1-\tau_{C, \text { DIFF }, V I S}\right)\left(1-\rho_{C, \text { DIFF VIS }}\right)\right]
\end{aligned}
$$

$S_{N, C, N I R, D I R}=R_{S}\left(1-f_{V I S}\right)\left[K_{b, N I R} f_{S C}\left(1-\tau_{C, D I R, N I R}\right)\left(1-\rho_{C, D I R, N I R}\right)\right]$

$S_{N, C, N I R, D I F F}=R_{S}\left(1-f_{V I S}\right)\left[\left(1-K_{b, N I R}\right) f_{D H C}\left(1-\tau_{C, D I F F, N I R}\right)\left(1-\rho_{C, D I F, N I R}\right)\right]$

where $R_{S}$ is the global incoming shortwave irradiance ( $\mathrm{W} \mathrm{m}^{-2}$ ), $f_{\text {VIS }}$ is the fraction of $R_{S}$ containing the visible spectra $\left(f_{V I S}=0.457\right.$ at the study location), $K_{b}$ is the fraction of direct beam irradiance in the visible or near infrared spectra, $f_{S C}$ is the solar - canopy view factor, $f_{D H C}$ is the downward hemispherical canopy view factor, $\tau_{C}$ is the canopy transmittance, $\rho_{C}$ is the canopy reflectance, and calculation procedures for $K_{b}, f_{S C}, f_{D H C}, \tau_{C}$, and $\rho_{C}$ are in Colaizzi et al. [46]. Similarly, $S_{N, S}$ is calculated as

$S_{N, S}=\left(T_{V I S, D I R}+T_{V I S, D I F F}\right)\left(1-\rho_{S, V I S}\right)+\left(T_{N I R, D I R}+T_{N I R, D I F F}\right)\left(1-\rho_{S, N I R}\right)$

where $T$ is the irradiance transmitted through the canopy to the soil surface $\left(\mathrm{W} \mathrm{m}^{-2}\right)$ and $\rho_{S}$ is the soil reflectance, and

$T_{V I S, D I R}=R_{S} f_{V I S}\left[K_{b, V I S}\left(f_{S C} \tau_{C, D I R, V I S}+1-f_{S C}\right)\right]$

$T_{V I S, D I F F}=R_{S} f_{V I S}\left[\left(1-K_{b, V I S}\right)\left(f_{D H C} \tau_{C, D I F, V I S}+1-f_{D H C}\right)\right]$

$T_{N I R, D I R}=R_{S}\left(1-f_{V I S}\right)\left[K_{b, N I R}\left(f_{S C} \tau_{C, D I R, N I R}+1-f_{S C}\right)\right]$

$T_{\text {NIR,DIFF }}=R_{S}\left(1-f_{V I S}\right)\left[\left(1-K_{b, N I R}\right)\left(f_{D H C} \tau_{C, D I F F, N I R}+1-f_{D H C}\right)\right]$.

The net longwave components are calculated as

$L_{N, C}=\left[\varepsilon_{C} L_{S K Y}+\varepsilon_{C} L_{S}-\left(1-\varepsilon_{S}\right) L_{C}\right] f_{D H C}\left(1-\theta_{L W}\right)$

$L_{N, S}=\varepsilon_{S} L_{S K Y}\left(1-f_{D H C}+f_{D H C} \theta_{L W}\right)+\varepsilon_{S} L_{C} f_{D H C}\left(1-\theta_{L W}\right)-\varepsilon_{S} L_{S}$

where

$\theta_{L W}=\exp \left(-\kappa_{L W} L A I \frac{\text { row }}{w_{C}}\right)$

and $w_{C}$ is the canopy width (m), row is the crop row spacing $(\mathrm{m}), \varepsilon_{C}$ and $\varepsilon_{S}$ are the canopy and soil emittance, respectively $\left(\varepsilon_{C}=\varepsilon_{S}=\right.$ 0.98; [48,64]), $L_{S K Y}$ is the longwave irradiance from the sky (W $\left.\mathrm{m}^{-2}\right), L_{S}$ and $L_{C}$ are the longwave irradiance from the soil and canopy, respectively $\left(\mathrm{W} \mathrm{m}^{-2}\right), \kappa_{L W}$ is the extinction coefficient for longwave irradiance $\left(\kappa_{L W}=0.95,[24]\right)$, and $L_{S K Y}, L_{S}$, and $L_{C}$ are calculated using the Stephan - Boltzmann relation

$L_{S K Y}=\varepsilon_{A T M} \sigma_{S B} T_{A}^{4}$

$L_{S}=\varepsilon_{S} \sigma_{S B} T_{S}^{4}$

$L_{C}=\varepsilon_{C} \sigma_{S B} T_{C}^{4}$

where $\varepsilon_{A T M}$ is the atmospheric emittance, $\sigma_{S B}$ is the Stephan-Boltzmann constant $\left.\left(\sigma_{S B}=5.67 \times 10^{-8} \mathrm{~W} \mathrm{~m}^{-2}\right) \mathrm{K}^{-4}\right)$, and all other terms are as defined in the main text. Note that all temperatures have $\mathrm{K}$ units, and $\varepsilon_{A T M}$ was calculated according to Idso [65]:

$\varepsilon_{\text {ATM }}=0.70+5.95 \times 10^{-4} e_{A} \exp \left(\frac{1500}{T_{A}}\right)$.

For the TSEB- $T_{R}$ version, $R_{N, S}$ and $R_{N, C}$ must be calculated first in order to calculate $T_{S}$ and $T_{C}$ (Appendix B), but the surface tempera- 
tures also appear in $L_{N, S}$ and $L_{N, c}$. Therefore, initial estimates of $R_{N}$ and $G$ were calculated according to Allen et al. [59], which only requires $T_{A}$ and not $T_{S}$ or $T_{C}$. Then $T_{C}$ is calculated using Eq. (7) in the main body of the paper, except $R_{N, C}$ is replaced with $\left(R_{N}-G\right)$, and $T_{S}$ is then calculated from Eq. (1). These initial $T_{S}$ and $T_{C}$ calculations are then used to calculate $L_{N, C}$ and $L_{N, S}$, followed by $R_{N, C}$ and $R_{N, S}$, which are then used in Appendix B to solve the series temperature - resistance equations, resulting in new $T_{S}$ and $T_{C}$. Additional iterations are possible by alternating between Appendix A and B. However, 1 to 5 iterations did not improve the performance of the TSEB$T_{R}$ model version in the current study (data not shown), and so the TSEB- $T_{R}$ results presented herein are for a single calculation of $R_{N, C}$ and $R_{N, S}$.

\section{Appendix B}

The original Norman et al. [23] formulation for the series resistance network (TSEB- $T_{R}$ model version; Fig. 1; Eq. (1) to (5)) used the Priestley-Taylor equation to calculate an initial estimate of canopy latent heat flux $\left(L E_{C}\right)$ under non-water-stressed conditions, and solved the resulting system of equations using the secant method. Here, we follow the same procedure, except a form of the Penman-Monteith equation replaces the Priestley-Taylor equation, which required modifications to Norman et al. [23]. The form of the Penman-Monteith equation used to calculate non-water-stressed $L E_{C}$ is

$L E_{C}=\frac{\Delta R_{N, C}}{\Delta+\gamma^{*}}+\frac{\rho C_{P}\left(e_{S}-e_{A}\right)}{r_{A}\left(\Delta+\gamma^{*}\right)}$

where all terms are as defined in the main text. Combining Eq. (B1) with (3a) and (5a) and solving for $T_{\mathrm{AC}}$ results in:

$T_{A C}=T_{C}-\frac{r_{X} \gamma^{*} R_{N, C}}{\rho C_{P}\left(\Delta+\gamma^{*}\right)}+\frac{r_{X}}{r_{A}} \frac{\left(e_{S}-e_{A}\right)}{\left(\Delta+\gamma^{*}\right)}$.

It should be emphasized that all temperature variables have units of K. Alternatively, $T_{\mathrm{AC}}$ can also be calculated in terms of only temperatures and resistances by considering that $H=H_{C}+H_{S}$ and combining Eq. (5a), (5b) and (5c):

$T_{A C}=\frac{\frac{T_{A}}{r_{A}}+\frac{T_{S}}{r_{S}}+\frac{T_{C}}{r_{X}}}{\frac{1}{r_{A}}+\frac{1}{r_{S}}+\frac{1}{r_{X}}}$

Combining Eqs. (1), (B2), and (B3) eliminates $T_{S}$ and $T_{A C}$ and results in a nonlinear expression in terms of $T_{C}$. An alternative approach is to employ the secant method, where $T_{C}$ is partitioned into linear $\left(T_{C, \text { LIN }}\right)$ and small correction $\left(\Delta T_{C}\right)$ components, so that

$T_{C}=T_{C . L I N}+\Delta T_{C}$

Expressions for $T_{C, L I N}$ and $\Delta T_{C}$ are then derived, and $T_{C}$ is calculated from Eq. (B4). The expression for $T_{C, L I N}$ is derived by rewriting Eq. (1) in its linear form,

$T_{R} \cong f_{V R} T_{C, L I N}+\left(1-f_{V R}\right) T_{S, L I N}$.

Eq. (B5) is solved for $T_{S, L I N}$ and substituted into Eq. (B3). Also, $T_{C}$ in Eq. (B2) and (B3) are replaced by $T_{C, \text { LIN }}$. Equating Eq. (B2) with (B3) and solving for $T_{C, L I N}$ results in

$T_{C, L I N}=\frac{\frac{T_{A}}{r_{A}}+\frac{T_{R}}{r_{S}\left(1-f_{V R}\right)}+\left[\frac{r_{x} \gamma^{*} R_{N, C}}{\rho C_{P}\left(\Delta+\gamma^{*}\right)}-\frac{r_{X}}{r_{A}} \frac{\left(e_{S}-e_{A}\right)}{\left(\Delta+\gamma^{*}\right)}\right]\left[\frac{1}{r_{A}}+\frac{1}{r_{S}}+\frac{1}{r_{X}}\right]}{\frac{1}{r_{A}}+\frac{1}{r_{S}}+\frac{f_{V R}}{r_{S}\left(1-f_{V R}\right)}}$

An expression for $\Delta T_{C}$ is derived by assuming $T_{C, L I N}>>\Delta T_{C}$ and $T_{S, L I N}>\Delta T_{S}$, so that the following approximations can be used:

$\left(T_{C, L I N}+\Delta T_{C}\right)^{4} \cong T_{C, L I N}^{4}+4 T_{c, L I N}^{3} \Delta T_{C}$

$\left(T_{S, L I N}+\Delta T_{S}\right)^{4} \cong T_{S, L I N}^{4}+4 T_{S, L I N}^{3} \Delta T_{S}$.
An expression for $T_{S, L I N}$ in terms of $T_{C, L I N}$ is derived by substituting Eq. (B5) into Eq. (B6):

$T_{S, L I N}=T_{C, L I N}\left(1+\frac{r_{S}}{r_{A}}\right)-T_{A} \frac{r_{S}}{r_{A}}-\left[\frac{r_{x} \gamma^{*} R_{N, C}}{\rho C_{P}\left(\Delta+\gamma^{*}\right)}-\frac{r_{X}}{r_{A}} \frac{\left(e_{S}-e_{A}\right)}{\left(\Delta+\gamma^{*}\right)}\right]\left[1+\frac{r_{S}}{r_{A}}+\frac{r_{S}}{r_{X}}\right]$.

By replacing the left hand side of Eq. (B8) with $T_{S^{-}} \Delta T_{S}$ (cf. Eq. (B4)) and combining Eqs. (B1), (3a) and (5a), it can be shown that

$\Delta T_{S}=\Delta T_{C}\left(1+\frac{r_{S}}{r_{A}}\right)$.

Substituting Eq. (B9) into (B7b), and substituting the right hand sides of (B7a) and (B7b) into (1) results in

$\Delta T_{C}=\frac{T_{R}^{4}-f_{V R} T_{C, L I N}^{4}-\left(1-f_{V R}\right) T_{S, L I N}^{4}}{4 f_{V R} T_{C, L I N}^{3}+4\left(1-f_{V R}\right) T_{S, L I N}^{3}\left(1+\frac{r_{S}}{r_{A}}\right)}$,

and $T_{C}$ can now be calculated using Eq. (B4), and $T_{S}$ is calculated by Eq. (1) (subject to the constraint that $T_{S} \geqslant T_{W}$ ). Since calculation of $r_{S}$ includes a convective term that is proportional to $T_{S}-T_{C}$ [24], and stability correction is used in calculating $r_{A}$ [24], $r_{S}$ and $r_{A}$ are recalculated, and then $T_{\mathrm{AC}}$ is calculated from Eq. (B3). With surface temperature components and resistances known, sensible and latent heat fluxes can now be calculated using Eq. (5) and (3), respectively.

It is possible that water stress, non-transpiring canopy elements, low vapor pressure deficit $\left(e_{S}-e_{A}\right)$, or a dry soil surface may result in overestimates of the initial $L E_{C}$, resulting $L E_{S}<0$ to compensate, and hence incorrect partitioning of available energy to the soil and canopy. This would imply condensation on the soil, which is unlikely in a semiarid climate during the day time (when $R_{N}>0$ ), even for fully irrigated surfaces. If $L E_{S}<0$, then $r_{C}$ [which is in $\left.\gamma *=\gamma\left(1+r_{C} / r_{A}\right)\right]$ is increased, and the energy balance is recalculated until $L E_{S} \geqslant 0$. In the current study, we increased $r_{C}$ in increments of $10 \mathrm{~s} \mathrm{~m}^{-1}$, up to $r_{C}=1000 \mathrm{~s} \mathrm{~m}^{-1}$ (The increment and upper limit were chosen arbitrarily; other values did not change final energy flux calculations). This is equivalent to incrementally decreasing the Priestley-Taylor parameter as described in Anderson et al. [25].

If $r_{C}=1000 \mathrm{~s} \mathrm{~m}^{-1}$ and $L E_{S}$ is still $<0$, then the soil may be nearly or completely dry, where $L E_{S} \approx 0$, and Eqs. (B1), (B6), (B9), (B10), and (B11) do not apply. This requires a new set of calculations where a dry soil is assumed. The equations in this case are unchanged from the original Norman et al. [23] procedure because they do not involve the Penman-Monteith-based estimate for $L E_{C}$, but they are nonetheless included here, with additional detail on their derivation that was not included in Norman et al. [23]. For a dry soil, a new constraint is imposed where $L E_{S}=0$, and from Eq. (3b),

$H_{S, 0}=R_{N, S}-G$

Combining Eqs. (1), (5b) and (B11) into (B3) eliminates $T_{S}$ and $T_{C}$ and results in a nonlinear expression in terms of $T_{\mathrm{AC}}$. As before with $T_{C}$, an alternative to calculating $T_{\mathrm{AC}}$ involves partitioning it into linear $\left(T_{A C, L I N}\right)$ and small correction $\left(\Delta T_{A C}\right)$ components, so that

$T_{A C}=T_{A C, L I N}+\Delta T_{A C}$

The expression for $T_{A C, L I N}$ is derived by rewriting Eq. (5b) as

$T_{S, L I N}=T_{A C, L I N}+\frac{H_{S, 0} r_{S}}{\rho C_{P}}$,

and combining with Eqs. (B5) and (B3), resulting in

$T_{A C, L I N}=\frac{\frac{T_{A}}{r_{A}}+\frac{T_{R}}{r_{X} f_{V R}}+\frac{H_{S, 0}}{\rho C_{P}}-\frac{H_{S, 0} r_{S}}{\rho C_{P}} \frac{\left(1-f_{V R}\right)}{r_{X} f_{V R}}}{\frac{1}{r_{A}}+\frac{1}{r_{X}}+\frac{\left(1-f_{V R}\right)}{r_{X} f_{V R}}}$. 
The expression for $\Delta T_{\mathrm{AC}}$ includes a new expression for $T_{C, L I N}$, which is derived by combining Eqs. (B5), (B13) and (B14), resulting in:

$T_{C, L I N}=T_{A C, L I N}\left[1+\frac{r_{X}}{r_{A}}\right]-T_{A} \frac{r_{X}}{r_{A}}-\frac{H_{S, 0} r_{X}}{\rho C_{P}}$.

The derivation for $\Delta T_{\mathrm{AC}}$ also requires that $\Delta T_{C}$ and $\Delta T_{S}$ be expressed in terms of $\Delta T_{\mathrm{AC}}$. For $\Delta T_{C}$, Eq. (B15) is rewritten where $T_{C, \text { LIN }}$ is replaced with $\left(T_{C}-\Delta T_{C}\right)$, and $T_{A C, L I N}$ is replaced with $\left(T_{\mathrm{AC}}-\Delta T_{A C}\right)$. From Eq. (5b),

$T_{A C}=T_{S}-\frac{H_{S, 0} r_{S}}{\rho C_{P}}$,

and it can be shown that

$\Delta T_{C}=\Delta T_{A C}\left(1+\frac{r_{X}}{r_{A}}\right)$

For $\Delta T_{S}$, Eq. (B13) is rewritten where $T_{S, L I N}$ and $T_{A C, L I N}$ are replaced by $\left(T_{S}-\Delta T_{S}\right)$ and $\left(T_{A C}-\Delta T_{A C}\right)$, respectively, resulting in

$\Delta T_{S}=\Delta T_{A C}$.

By combining Eqs. (1), (B7), (B16) and (B17), it can be shown that

$\Delta T_{A C}=\frac{T_{R}^{4}-f_{V R} T_{C, L I N}^{4}-\left(1-f_{V R}\right) T_{S, L I N}^{4}}{4 f_{V R}\left(1+\frac{r_{X}}{r_{A}}\right) T_{C, L I N}^{3}+4\left(1-f_{V R}\right) T_{S, L I N}^{3}}$

where $T_{S, L I N}$ and $T_{C, L I N}$ are calculated with Eqs. (B13) and (B15), respectively. $T_{\mathrm{AC}}, T_{S}$, and $T_{C}$ are now be calculated using Eqs. (B12), (B16) and (1), respectively, $r_{S}$ and $r_{A}$ are recalculated subject to the new $T_{S}$ and $T_{C}$ values, and the energy balance is recalculated with Eq. (3) and (5), subject to the constraint that $L E_{C} \geqslant 0$ (for a completely dry surface, both $L E_{S}$ and $L E_{C}$ can be zero). Using the new $r_{S}$ and $r_{A}$, the calculation procedure for dry soil can be repeated until a specified convergence is obtained; in the current study this was $\left|r_{S, i}-r_{S, i+1}\right|<0.01$ for a maximum of 100 iterations.

\section{References}

[1] Tolk JA, Howell TA, Steiner JL, Krieg DR, Schneider AD. Role of transpiration suppression by evaporation of intercepted water in improving irrigation efficiency. Irrig Sci 1995;16:89-95.

[2] Todd RW, Klocke NL, Hergert GW, Parkhurst AM. Evaporation from soil influenced by crop shading, crop residue, and wetting regime. Trans ASAE $1991 ; 34: 461-6$

[3] Lascano RJ, Baumhardt RL. Effects of crop residue on soil and plant water evaporation in a dryland cotton system. Theor Appl Meteorol 1996;54:69-84

[4] Steiner JL. Dryland grain sorghum water use, light interception, and growth responses to planting geometry. Agron J 1986;78:720-6.

[5] Steiner JL. Radiation balance of dryland grain sorghum as affected by planting geometry. Agron J 1987;79:259-65.

[6] Sauer TJ, Singer JW, Prueger JH, DeSutter TM, Hatfield JL. Radiation balance and evaporation partitioning in a narrow-row soybean canopy. Agric For Meteorol 2007; $145: 206-14$

[7] Colaizzi PD, Schneider AD, Evett SR, Howell TA. Comparison of SDI, LEPA, and spray irrigation performance for grain sorghum. Trans ASAE 2004:47(5):1477-92.

[8] Ortega-Farias S, Poblete-Echeverría C, Brisson N. Parameterization of a twolayer model for estimating vineyard evapotranspiration using meteorological measurements. Agric For Meteorol 2010;150:276-86.

[9] Ham JM, Heilman JL, Lascano RJ. Soil and canopy energy balances of a row crop at partial cover. Agron J 1991;83:744-53.

[10] Ham JM, Heilman JL. Aerodynamic and surface resistances affecting energy transport in a sparse crop. Agric For Meteorol 1991;53:267-84.

[11] Heilman JL, McInnes KJ, Savage MJ, Gesch RW, Lascano RJ. Soil and canopy energy balances in a west Texas vineyard. Agric For Meteorol 1994;71(1994):99-114.

[12] Lund MR, Soegaard H. Modelling of evaporation in a sparse millet crop using a two-source model including sensible heat advection within the canopy. J Hydrol 2003;280:124-44.

[13] Agam N, Evett SR, Tolk JA, Copeland KS, Howell TA, Colaizzi PD, et al Evaporative loss from irrigated interrows in a highly advective semi-arid agricultural area. Adv Water Resour 2012;50:20-30.

[14] Evett SR. Introduction: can water use efficiency be modeled well enough to impact crop management? Agron J 2009;101:423-5.

[15] Shuttleworth WJ, Wallace JS. Evaporation from sparse crops-an energy combination theory. Quart J Royal Meteorol Soc 1985;111:839-55.
[16] Shuttleworth WJ, Gurney RJ. The theoretical relationship between foliage temperature and canopy resistance in sparse crops. Quart J Royal Meteorol Soc 1990;116:497-519.

[17] Kustas WP, Anderson MC, Norman JM, II F. Utility of radiometric-aerodynamic temperature relations for heat flux estimation. Boundary Layer Meteorol 2007;122:167-87.

[18] Kalma JD, McVicar TR, McCabe MF. Estimating land surface evaporation: A review of methods using remotely sensed surface temperature data. Surv Geophys 2008. http://dx.doi.org/10.1007/s10712-008-9037-z.

[19] Li Z, Tang R, Wan Z, Bi Y, Zhou C, Tang B, Yan G, Zhang X. A review of current methodologies for regional evapotranspiration estimation from remotely sensed data. Sensors 2009;9:3801-53.

[20] Francois C, Ottle C, Prevot L. Analytical parameterization of canopy directional emissivity and directional radiance in the thermal infrared. Applications on retrieval of soil and foliage temperatures using two directional measurements. Int J Rem Sens 1997;18(12):2587-621.

[21] Chehbouni A, Nouvellon Y, Lhomme J-P, Watts C, Boulet G, Kerr YH, et al. Estimation of surface sensible heat flux using dual angle observations of radiative surface temperature. Agric For Meteorol 2001;108:55-65.

[22] Merlin O, Chehbouni A. Different approaches in estimating heat flux using dual angle observations of radiative surface temperature. Int J Remote Sens 2004;25:275-89.

[23] Norman JM, Kustas WP, Humes KS. A two-source approach for estimating soil and vegetation energy fluxes from observations of directional radiometric surface temperature. Agric For Meteorol 1995;77:263-93.

[24] Kustas WP, Norman JM. Evaluation of soil and vegetation heat flux predictions using a simple two-source model with radiometric temperatures for partial canopy cover. Agric For Meteorol 1999;94:13-29.

[25] Anderson MC, Norman JM, Kustas WP, Li F, Prueger JH, Mecikalski JM. Effects of vegetation clumping on two-source model estimates of surface energy fluxes from an agricultural landscape during SMACEX. J Hydrometeorol 2005;6:892-909.

[26] Kustas WP, Anderson MC. Advances in thermal infrared remote sensing for land surface modeling. Agric For Meteorol 2009;149:2071-81.

[27] Kustas WP. Estimates of evapotranspiration with a one- and two-layer model of heat transfer over partial canopy cover. J Appl Meteorol 1990;29:704-15.

[28] Kustas WP, Norman JM. A two-source energy balance approach using directional radiometric temperature observations for sparse canopy covered surfaces. Agron J 2000;92:847-54.

[29] Norman JM, Kustas WP, Prueger JH, Diak GR. Surface flux estimation using radiometric temperature: a dual temperature difference method to minimize measurement error. Water Resour Res 2000;36:2263-74.

[30] Li F, Kustas WP, Prueger JH, Neale CMU, Jackson TJ. Utility of remote sensing based two-source energy balance model under low and high vegetation cover conditions. J Hydromet 2005;6:878-91.

[31] French AN, Hunsaker DJ, Clarke TR, Fitzgerald GJ, Luckett WE, Pinter Jr PJ. Energy balance estimation of evapotranspiration for wheat grown under variable management practices in Central Arizona. Trans ASABE 2007;50(6):2059-71.

[32] Timmermans WJ, Kustas WP, Anderson MC, French AN. An intercomparison of the surface energy balance algorithm for land (SEBAL) and the two-source energy balance (TSEB) modeling schemes. Remote Sens Environ 2007; 108:369-84

[33] Choi M, Kustas WP, Anderson MC, Allen RG, Li F, Kjaersgaard JH. An intercomparison of three remote sensing-based surface energy balance algorithms over a corn and soybean production region (Iowa, US) during SMACEX. Agric For Meteorol 2009;149:2082-97.

[34] Gonzalez-Dugo MP, Neale CMU, Mateos L, Kustas WP, Prueger JH, Anderson $\mathrm{MC}$, et al. A comparison of operational remote sensing-based models for estimating crop evapotranspiration. Agric For Meteorol 2009;149:1843-53.

[35] Tang R, Li Z, Jia Y, Li C, Sun X, Kustas WP, Anderson MC. An intercomparison of three remote sensing-based energy balance models using large aperture scintillometer measurements over a wheat-corn production region. Remote Sens Environ 2011;115:3187-202.

[36] Kustas WP, Norman JM. A two-source approach for estimating turbulent fluxes using multiple angle thermal infrared observations. Water Resour Res 1997;33:1495-508.

[37] Sánchez JM, Kustas WP, Caselles V, Anderson MC. Modelling surface energy fluxes over maize using a two-source patch model and radiometric soil and canopy temperature observations. Remote Sens Environ 2008;112:1130-43.

[38] Marek TH, Schneider AD, Howell TA, Ebeling LL. Design and construction of large weighing monolithic lysimeters. Trans ASAE 1988;31:477-84.

[39] Howell TA, Schneider AD, Dusek DA, Marek TH, Steiner JL. Calibration and scale performance of Bushland weighing lysimeters. Trans ASAE 1995;38(4):1019-24.

40] Todd RW, Evett SR, Howell TA. The Bowen ratio-energy balance method for estimating latent heat flux of irrigated alfalfa evaluated in a semi-arid advective environment. Agric For Meteorol 2000;103(4):335-48.

41] Twine TE, Kustas WP, Norman JM, Cook DR, Houser PR, Meyers TP, et al. Correcting eddy-covariance flux underestimates over a grassland. Agric For Meteorol 2000;103(3):279-300.

[42] Alfieri JG, Kustas WP, Prueger J, Hipps LE, Evett SR, Basara JB et al. On the discrepancy between eddy covariance and lysimetry-based surface flux measurements under strongly advective conditions, Adv Water Resour 2012;50:62-78.

[43] Evett SR. Neutron moisture meters, In: Evett SR, Heng LK, Moutonnet P, Nguyen ML, (Eds.), Field estimation of soil water content: a practical guide to 
methods, instrumentation, and sensor technology, Vienna: Int Atomic Energy Agency, IAEA-TCS-30, 2008, p. 39-54.

[44] Evett SR, Schwartz RC, Howell TA, Baumhardt, Copeland KS, Can weighing lysimeter ET represent surrounding field ET well enough to test flux station measurements of daily and sub-daily ET?. Adv Water Resour, 2012;50:79-90.

[45] Colaizzi PD, O'Shaughnessy SA, Gowda PH, Evett SR, Howell TA, Kustas WP, et al. Radiometer footprint model to estimate sunlit and shaded components for row crops. Agron J 2010;102:942-55.

[46] Colaizzi PD, Li F, Kustas WP, Anderson MC, Evett SR, Howell TA. Radiation model for row crops - 1: Geometric model description and parameterization. Agron J 2012;104:225-40.

[47] Colaizzi PD, Schwartz RC, Evett SR, Howell TA, Gowda PH, Tolk JA. Radiation model for row crops - 2: Model evaluation. Agron J 2012;104:241-55.

[48] Campbell GS, Norman JM. An introduction to environmental biophysics. New York: Springer-Verlag; 1998.

[49] Santanello JA, Friedl MA. Diurnal variation in soil heat flux and net radiation. J Appl Meteorol 2003;42:851-62.

[50] Evett SR. Water and energy balances at soil-plant-atmosphere interfaces. In: Warrick AA, editor. The soil physics companion. New York: CRC Press; 2002. p. 127-88.

[51] Kustas WP, Norman JM, Schmugge TJ, Anderson MC. Mapping surface energy fluxes with radiometric temperature. In: Quattrochi DA, Luvall JC, editors. Thermal remote sensing in land surface processes. New York: CRC Press; 2004.

[52] O'Shaughnessy SA, Evett SR. Developing wireless sensor networks for monitoring crop canopy temperature using a moving sprinkler system as a platform. Appl Eng Agric 2010;26(2):331-41.

[53] Priestley CHB, Taylor RJ. On the assessment of surface heat flux and evaporation using large-scale parameters. Mon Weather Rev 1972;100:81-92.

[54] Agam N, Kustas WP, Anderson MC, Norman JM, Colaizzi PD, Howell TA, et al. Application of the Priestley-Taylor approach in a two-source energy balance model. J Hydromet 2010;11:185-98.

[55] Jackson RD, Idso SB, Reginato RJ, Pinter Jr PJ. Canopy temperatures as a crop water stress indicator. Water Resour Res 1981;17:1133-8.

[56] Allen RG, Pruitt WO, Wright JL, Howell TA, Ventura F, Snyder R, et al. A recommendation on standardized surface resistance for hourly calculation of reference ETo by the FA056 Penman-Monteith method. Agric Water Manag 2006;81:1-22.

[57] Kustas WP, Alfieri JG, Anderson MC, Colaizzi PD, Prueger JH, Evett SR et al., Evaluating the two-source energy balance model using local thermal and surface flux observations in a strongly advective irrigated agricultural area, Adv Water Resour 2012;50:120-133.
[58] Wanjura DF, Upchurch DR, Time thresholds for canopy temperature-based irrigation. In: CR Camp, EJ Sadler, RE Yoder (Eds.), Evapotranspiration and irrigation scheduling proceedings international conference, San Antonio, TX, ASAE, 1996, p. 295-303.

[59] Allen RG, Pereira LS, Raes D, Smith M, Crop evapotranspiration: guidelines for computing crop water requirements, Food and agric org paper no. 56. Rome: food and agric org of the united nations, 1998.

[60] Tolk JA, Evett SR, Howell TA. Advection influences on evapotranspiration of alfalfa in a semiarid climate. Agron J 2006;98:1646-54.

[61] USDA-NRCS, Web soil survey, soil survey TX375, Potter County, Texas, Natural resources conservation service, Washington, D.C., Accessed 8 Aug 2011. $<$ http://websoilsurvey.nrcs.usda.gov>.

[62] Schneider AD, Howell TA. Surface runoff due to LEPA and spray irrigation of a slowly permeable soil. Trans ASAE 2000;43(5):1089-95.

[63] Norman JM, Becker F. Terminology in thermal infrared remote sensing of natural surfaces. Rem Sens Rev 1995;12:159-73.

[64] Idso SB, Jackson RD, Ehrler WL, Mitchell ST. A method for determination of infrared emittance of leaves. Ecology 1969;50(5):899-902.

[65] Idso SB. A set of equations for full spectrum and 8- to 14- $\mu \mathrm{m}$ and 10.5- to $12.5 \mu \mathrm{m}$ thermal radiation from cloudless skies. Water Resour Res 1981;17:295-304.

[66] Wanjura DF, Maas SJ, Winslow JC, Upchurch DR. Scanned and spot measured canopy temperatures of cotton and corn. Comp Elect Agric 2004;44: 33-48.

[67] Legates DR, McCabe Jr GJ. Evaluating the use of goodness-of-fit measures in hydrologic and hydroclimatic model validation. Water Resour Res 1999;35(1):233-41.

[68] Ham JM, Kluitenberg GJ. Positional variation in the soil energy balance beneath a row-crop canopy. Agric For Meteorol 1993;63:73-92.

[69] Agam N, Kustas WP, Evett SR, Colaizzi PD, Cosh M, McKee LG, Soil heat flux variability influenced by row direction in irrigated cotton, Adv Water Resou $r$ 2012;50:31-40.

[70] Kimes DS, Idso SB, Pinter Jr PJ, Reginato RJ, Jackson RD. View angle effects in the radiometric measurement of plant canopy temperature. Rem Sen Environ 1980;10:273-84.

[71] Wanjura DF, Upchurch DR. Infrared thermometer calibration and viewing method effects on canopy temperature measurement. Agric For Meteorol 1991;55:309-21.

[72] Thanisawanyangkura S, Sinoquet H, Rivet P, Cretenet M, Jallas E. Leaf orientation and sunlit leaf area distribution in cotton. Agric For Meteorol 1997;86:1-15. 